\title{
Role of convection-circulation coupling in the propagation mechanism of the Madden-Julian Oscillation over the Maritime Continent in a climate model
}

\author{
Yi-Chi Wang ${ }^{1} \cdot$ Wan-Ling Tseng ${ }^{1}$ (D) Huang-Hsiung Hsu ${ }^{1}$
}

Received: 18 March 2021 / Accepted: 17 October 2021 / Published online: 8 November 2021

(c) The Author(s) 2021

\begin{abstract}
This study investigates the role of convection-circulation coupling on the simulated eastward propagation of the MaddenJulian Oscillation (MJO) over the Maritime Continent (MC). Experiments are conducted with the European Centre Hamburg Model Version 5 (ECHAM5) coupled with the one-column ocean model-Snow-Ice-Thermocline (SIT) and two different cumulus schemes, Nordeng-Tiedtke (E5SIT-Nord) and Tiedtke (E5SIT-Tied). During the early phase of MJO composites, the E5SIT-Nord simulation reveals stronger intraseasonal anomalies in the apparent heat source $\left(Q_{1}\right)$ over the convective center, however, the E5SIT-Tied produces a stronger background $Q_{1}$, suggesting that deep convection prevails over the MC but does not couple with the MJO circulation. Similarly, in the E5SIT-Tied simulation, in-column moisture is kept mostly by local deep convection over the MC, which is in contrast to the well-correlated relationship between moisture anomaly and MJO circulation in E5SIT-Nord. A case study based on an observational MJO reveals similar biases concerning of convection-circulation coupling emerges within a few days of simulations. The E5SIT-Tied simulation produces weaker heating at the convective center of the MJO than the E5SIT-Nord a few days after model initiation, resulting weaker subsidence to the east and less favorable for propagation. The present findings highlight the instantaneous responses of cumulus parameterization schemes to MJO-related environmental changes can further affect intraseasonal variability through altering convection-circulation coupling over the MC. Physical schemes of moist convection are essential to realistically represent this coupling and thereby improve the simulation of the eastward propagation of the MJO.
\end{abstract}

Keywords $\mathrm{MJO} \cdot$ Convection scheme $\cdot$ Low-level moistening $\cdot$ Climate models

\section{Introduction}

The Madden-Julian Oscillation (MJO) is the dominant pattern of atmospheric intraseasonal variability in the tropics (Madden and Julian 1972; Zhang 2005; Jiang et al. 2020). Numerous observational and modeling studies have explored the fundamental physics regarding the eastward propagation and development of the MJO, including the interaction with the frictional boundary layer (Wang and Rui 1990; Salby and Hendon 1994; Maloney and Hartmann 1998; Hsu et al. 2004; Kang et al. 2013), convective intraseasonal air-sea interactions (Flatau et al. 1997; Waliser et al. 1999), ocean

Wan-Ling Tseng

wtseng@gate.sinica.edu.tw

1 Research Center for Environmental Changes, Academia Sinica, Taipei, Taiwan surface flux (Maloney and Sobel 2004; Maloney 2009; Kiranmayi and Maloney 2011; Andersen and Kuang 2012), moisture transport by cumulus (Benedict and Randall 2007; Jiang et al. 2016; Jiang 2017), and air-sea interaction (DeMott et al. 2015, 2019). Despite the considerable progress in state-of-the-art general circulation models (GCMs) in recent decades, realistic simulations of the MJO remain difficult.

One challenge to improving models is the MJO is organized by strong coupling between MJO circulations, convection, and ocean thermodynamics. Studies have addressed numerous crucial physical processes for reproducing the MJO in GCMs, including the mean state (Kim et al. 2011; Kim 2017; Jiang et al. 2018; Klingaman and Demott 2020), convection simulated by cumulus parameterization schemes (CPS; Liu et al. 2005; Deng and Wu 2010; Zhou et al. 2012), convectively coupled tropical waves (Kiladis et al. 2005; Janiga et al. 2018), ocean-atmosphere interaction (DeMott 
et al. 2015, 2019; Tseng et al. 2015), the diurnal cycle of sea surface temperature (SST; Bernie et al. 2005; Klingaman et al. 2011), and cloud radiative feedback (Jiang et al. 2011; DelGenio and Chen 2015; Ciesielski et al. 2017). These findings jointly reflect the complexity of the physical processes involved in understanding and simulating the MJO.

To untangle this multifaceted problem, all coupling mechanisms must be carefully examined. One key aspect of the MJO behavior manifested of such coupling is MJO's eastward propagation from the Indian Ocean to the Maritime Continent (MC) and onward to the western Pacific (Zhang 2005). The eastward propagation of the MJO over the MC has been challenging to simulate in GCMs, and remains so, even with improvements found in the Coupled Model Intercomparison Project Phase 6 models (CMIP6; Ahn et al. 2020a, b; Fiedler et al. 2020). After the MJO appears over the Indian Ocean, deep convection in the oscillation induces the dynamic processes associated with the equatorial wavelike perturbations to the east over the MC, further enhancing both low-level moisture convergence and moistening (Zhang 2005; Jiang et al. 2020). Observational studies have suggested that the shallow convection with bottom-heavy heating profiles that occurs before the propagation of the MJO convective center helps precondition the development of deep convection (Kemball-Cook and Wang 2001; Kikuchi and Takayabu 2004). Such shallow convection that is associated with low-level convergence and ascending motion moistens the lower troposphere and enhances coupling with intraseasonal perturbations (Benedict and Randall 2011; Lappen and Schumacher 2014). In a model experiment with prescribed heating profiles, Lappen and Schumacher (2014) also demonstrated the essential role of the low-level heating in the development and maintenance of the MJO.

Multiple studies have also reported that including air-sea coupling aids MJO simulation in climate models (Tseng et al. 2015; Jiang et al. 2015, 2019; DeMott et al. 2018, 2019). Crueger et al. (2013) explored the role of CPS, ocean coupling, and model resolution by evaluating the simulation of the MJO with the European Centre Hamburg Model (ECHAM) Version 6 under various configurations. They have found that CPS plays an essential role in simulating MJO signatures, along with ocean coupling. The researchers attributed the discrepancy to differences in the sensitivity of the two CPS to tropospheric moisture (Crueger et al. 2013). However, they did not discuss the role of convection-circulation coupling in their analysis. By jointly using the ECHAM5 and their self-developed one-column ocean model, the Snow-Ice-Thermocline (SIT) model, Tseng et al. (2015) successfully simulated the eastward propagation of the MJO, observing that the low-level moisture convergence prior to the active MJO phase over the $\mathrm{MC}$ played a pivotal role in preconditioning the propagation of deep convection and circulation. They found that the upper oceanic warm layer to the east of organized deep convection gets warmer with more incident solar radiation and reduced evaporative cooling over the subsidence region. The resulting warm SST ahead of the MJO was suggested to destabilize the boundary layer and enhance frictional convergence, underscoring the importance of shallow moistening for the further development of the MJO (Tseng et al. 2015). Comparing between models, Jiang et al. (2015) reported that the ECHAM5-SIT model was one of the best GCMs in MJO simulations. In another study, that model was used to determine the role of air-sea coupling in MJO simulations (DeMott et al. 2019). Although both studies have evaluated the performance of the model in simulating the MJO, the contribution of convection has not been addressed. Thus, the key mechanism underlying convection-circulation coupling, which may improve MJO simulations, remains unclear.

To examine the role of convection in the mechanism of MJO propagation over the MC, we use the model setup described by Tseng et al. (2015) to investigate the convection-circulation coupling in the ECHAM5 model experiments with two CPSs, namely the Nordeng-Tiedtke scheme (E5SIT-Nord) and the Tiedtke scheme (E5SIT-Tied). By using the model setup with a high resolution one column ocean model, we can investigate the role of convection-circulation coupling for simulating the eastward propagation of MJO in GCMs without interferences of possible biases from air-sea coupling. Our analysis will mainly focus on the role of oceanic convection over the $\mathrm{MC}$ regions for $\mathrm{MJO}$ propagation. Besides the advantage provided by ECHAM5SIT, this analysis focus is based on the fact that oceanic convection over MC plays an important role in sustaining MJO-scale circulation, while the land convection is found to compete with MJO-related convection in both observations and models (Hagos et al. 2016; Ahn et al. 2020a). How the land convective activity may affect the MJO propagation will be a great topic for future study.

In this study, we adopted the budget analysis of apparent heat sources $\left(Q_{1}\right)$ and apparent moisture sinks $\left(Q_{2}\right)$, as well as the moist static energy (MSE) budget, to the 25-year climate simulations of two model setup, with the central aim of identifying the contribution of the moisture buildup over the $\mathrm{MC}$ in the propagation of the MJO. To further clarify the effects of the representation of CPS on MJO propagation, we conduct a case study by using the initial conditions from the ERA-Interim reanalysis and examining the MJO evolution simulated by the two CPSs. By observing how the model biases evolve in case study provides more information about how biases in climate runs may link to the fast physics from CPS related to convection-circulation coupling. The remainder of this paper is organized as follows. The data, model, and methodology are described in Sect. 2. Sections 3 and 4 present the analytical results and the results from the 
case study, respectively. The discussion and conclusion are in Sects. 5 and 6, respectively.

\section{Data, models, and methodology}

In the present study, the ECHAM5 (Roeckner et al. 2003, 2006) is used in combination with the SIT (Tu and Tsuang 2005; Tsuang et al. 2009). As its name implies, the ECHAM5 is the fifth version of the ECHAM, a GCM developed at the Max Planck Institute for Meteorology. The horizontal resolution used is T63 $\left(\sim 1.8^{\circ}\right)$, with 31 vertical layers and a model top at $10 \mathrm{hPa}$ (approximately $30 \mathrm{~km}$ ). Although not the most updated version of ECHAM, previous studies have found that, when coupling with SIT, ECHAM5 can realistically simulate many critical features and processes of MJO (Tseng et al. 2015; DeMott et al. 2019). ECHAM5-SIT also had been used to participate in the model intercomparison study hosted by the MJO task Force, under the auspices of Year of Tropical Convection and later the Working Group on Numerical Experimentation, and was identified as one of the better skill models for MJO simulations in many studies (Jiang et al. 2015; Wang et al. 2017; Zhu and Li 2020; Heath et al. 2021).

SIT simulates the SSTs and variability in upper ocean temperature, including that attributable to the cool-skin and diurnal warm-layer effects in the upper ocean. The turbulent kinetic energy of a water column is also simulated (Gaspar et al. 1990). In our experiments, SIT has 42 vertical layers, 12 of which are in the upper $10 \mathrm{~m}$. In one study (Tu and Tsuang 2005), the SIT, with a $1 \mathrm{~m}$ resolution in the upper $10 \mathrm{~m}$ and a layer at $0.05 \mathrm{~mm}$ for reproducing the cool-skin effects at the ocean surface, realistically simulated the near-surface warm layer (Tu and Tsuang 2005). It is not conventional to combine such a high-vertical-resolution ocean model of turbulent kinetic energy to an atmospheric GCM (AGCM). To account for horizontal processes, the ocean model is weakly nudged (with a 30-day time scale) at depths exceeding $10 \mathrm{~m}$ and strong nudged (with a 1-day time scale) below $100 \mathrm{~m}$ to the observed climatological ocean temperature. The SIT and ECHAM exchange SST and surface fluxes at every time step $(12 \mathrm{~min})$ in the tropics $\left(30^{\circ} \mathrm{S}-30^{\circ} \mathrm{N}\right)$. Elsewhere, climatological SST drives the AGCM.

Two CPS used in the present study are the NordengTiedtke scheme, the default scheme used in the ECHAM5 (Nordeng 1994), and the Tiedtke scheme (Tiedtke 1989). The Nordeng-Tiedtke scheme, an improved version of the Tiedtke mass flux convection scheme, considers organized entrainment and detrainment in buoyancy-related penetrative convection (Nordeng 1994). The differences between the two schemes lie mainly in the representation of deep convection regimes, particularly closures and entrainment rates (Möbis and Stevens 2012). For closures, the Tiedtke scheme uses the moisture convergence within the subcloud layer to make approximation for convective intensity (Tiedtke 1989). By contrast, the Nordeng-Tiedtke scheme uses the quasiequilibrium closure for the relaxation of the vertically integrated buoyancy (Nordeng 1994). For the entrainment rate, the Nordeng-Tiedtke scheme uses additional lateral mixing; specifically, the buoyancy-driven entrainment for deep convection is included in the organized entrainment module (Nordeng 1994).

In the present study, the simulation results are compared to data from the Global Precipitation Climatology Project (GPCP: Adler et al. 2003), data on outgoing longwave radiation and daily Optimum Interpolation SST from the National Oceanic and Atmosphere Administration (Banzon et al. 2014), and atmospheric states from the ERA-Interim reanalysis (Dee et al. 2011). We used 22-year ERA-Interim reanalysis from 1989 to 2010 and 14-year GPCP dataset from 1997 to 2010. The simulation diagnostics package developed by the Climate Variability and Predictability MJO Working Group (CLIVAR Madden-Julian Oscillation Working Group 2009) and a 20-to-100-day filter are used to isolate and determine intraseasonal variability. The MJO phases are classified on the basis of the Real-time Multivariate MJO (RMM) index, which uses the principal components (PCs) of the two leading pairs of empirical orthogonal function modes of intraseasonal outgoing longwave radiation and zonal winds at 850 and $200 \mathrm{hPa}$ between $15^{\circ} \mathrm{S}$ and $15^{\circ} \mathrm{N}$ to represent MJO features (Wheeler and Hendon 2004). Because of the strong eastward propagation tendency of the $\mathrm{MJO}$, the analysis is centered on the boreal cool season (November-April). The total simulation length of each experiment is 25 years, with data in the last 24 years subjected to analysis.

To understand the simulated convection, we calculate the $Q_{1}$ and $Q_{2}$ associated with the MJO (Yanai et al. 1973), which are presented in the following equations:

$$
\begin{aligned}
& Q_{1} \equiv \frac{\partial \bar{s}}{\partial t}+v \cdot \nabla \bar{s}+\bar{\omega} \frac{\partial \bar{s}}{\partial p}=Q_{R}+L_{v}(\bar{c}-\bar{e})-\frac{\partial}{\partial p} \overline{s^{\prime} \omega^{\prime}} \\
& Q_{2} \equiv-L_{v}\left(\frac{\partial \bar{q}}{\partial t}+v \cdot \nabla \bar{q}+\bar{\omega} \frac{\partial \bar{q}}{\partial p}\right)=L_{v}(\bar{c}-\bar{e})+L_{v} \frac{\partial}{\partial p} \overline{q^{\prime} \omega^{\prime}}
\end{aligned}
$$

where $v$ represents horizontal winds, $\omega$ represents vertical pressure velocity, $c$ and $e$ represent condensation and evaporation, respectively; $q$ is the water vapor mixing ratio; $s$ is the dry static energy $\left(s=c_{p} T+g z\right.$, where $c_{p}$ is specific heat capacity, $T$ is temperature, $g$ is gravitational constant, and z is height); and $L_{v}$ is the latent heat of vaporization. As for $(\cdot)$, it denotes the grid scale quantity relative to the subgrid components. For the convection-dominated regions, convective activities could be inferred by comparing the $Q_{1}$ and $Q_{2}$ vertical profiles to reflect the vertical transport of the MSE by convection. For example, deep convection regimes often 
(a) Observations

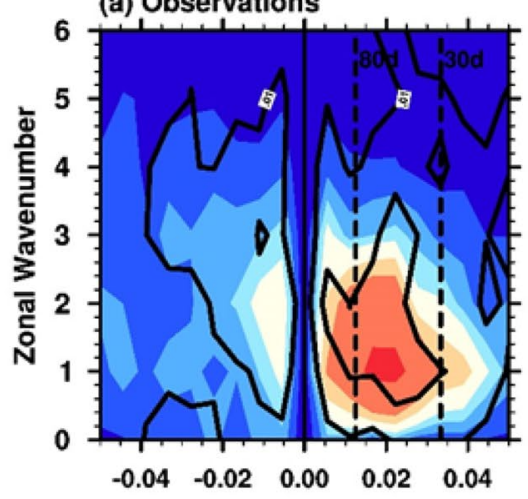

(d) Observations

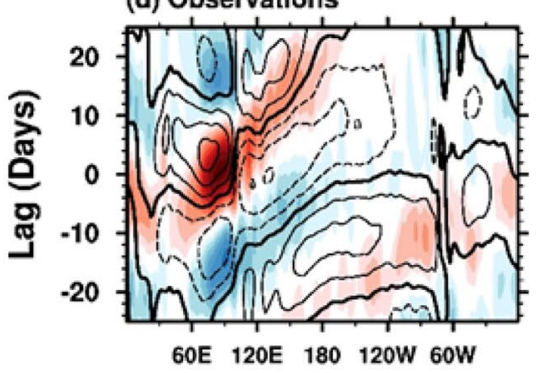

(b) E5SIT-Nord

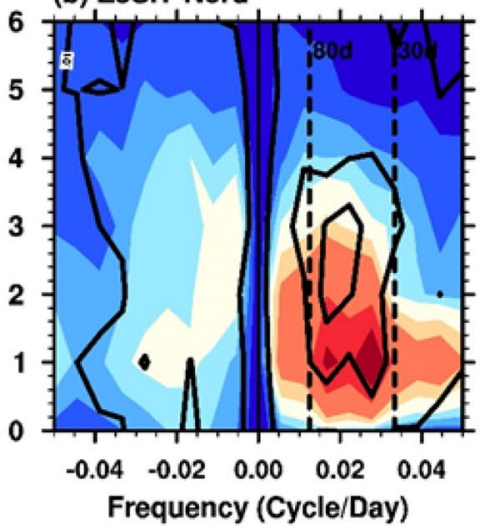

(e) E5SIT-Nord

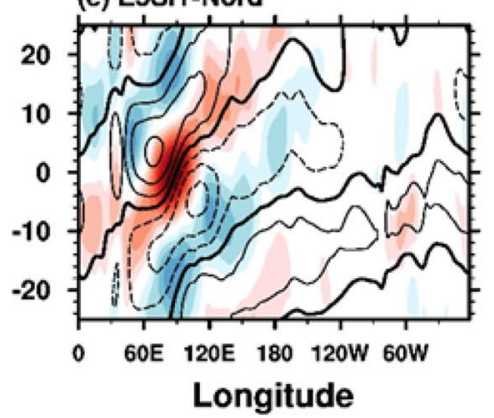

(c) E5SIT-Tied

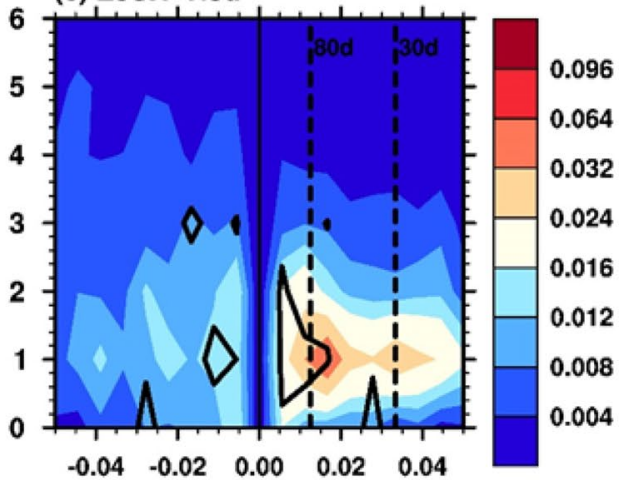

Fig. 1 a-c Wavenumber-frequency spectra of $850 \mathrm{hPa}$ equatorial zonal winds (shaded area) and precipitation (contour) over $10^{\circ} \mathrm{S}-10^{\circ}$ $\mathrm{N}$. The contour lines are 0.01, 0.03 and 0.05. d-f Lag-longitude diagrams of intraseasonal precipitation (shaded area) and $10 \mathrm{~m}$ zonal

have top-heavy $Q_{1}$ vertical profiles with peaks at approximately $300 \mathrm{hPa}$ and $Q_{2}$ profiles with peaks at $700 \mathrm{hPa}$, indicative of upward convective transport from the lower troposphere (Yanai et al. 1973). By contrast, $Q_{1}$ vertical profiles in shallow convection regimes tend to be bottomheavy, with peaks at lower atmospheric pressures (Nitta and Esbensen 1974).

The vertically integrated MSE budget is defined as follows:

$$
\begin{aligned}
\left\langle\frac{\partial h}{\partial t}\right\rangle^{\prime}= & -\left\langle u \frac{\partial h}{\partial x}\right\rangle^{\prime}-\left\langle v \frac{\partial h}{\partial y}\right\rangle^{\prime}-\left\langle\omega \frac{\partial h}{\partial p}\right\rangle^{\prime} \\
& +\langle L W\rangle^{\prime}+\langle S W\rangle^{\prime}+\langle L H F\rangle^{\prime}+\langle S H F\rangle^{\prime}
\end{aligned}
$$

where $h$ is the MSE $\left(h=c_{p} T+g z+L_{v} q\right) ; u$ and $v$ are the zonal and meridional velocities, respectively; $\omega$ is the vertical pressure velocity; $L W$ and $S W$ are the longwave and shortwave radiation fluxes, respectively; and $L H F$ and $S H F$ are the latent and sensible surface heat fluxes, respectively. The mass-weighted vertical integration from the surface to $200 \mathrm{hPa}$ is denoted by $\langle\cdot\rangle$, and intraseasonal anomalies are represented by $\langle\cdot\rangle$ '. All fields are isolated using a 20-to100-day band-pass Lanczos filter (Duchon 1979). winds (contour) correlated with precipitation averaged over $10^{\circ} \mathrm{S}-5^{\circ}$ $\mathrm{N}, 75^{\circ} \mathrm{E}-100^{\circ} \mathrm{E}$. The contour interval is 0.2 . Solid lines are positive and dash lines are negative value

\section{ECHAM-SIT simulations of the MJO}

The simulations of the MJO in two experiments involving the E5SIT-Nord and E5SIT-Tied are examined in this section. Figure $1 \mathrm{a}-\mathrm{c}$ presents the wavenumber-frequency spectra of simulated $850 \mathrm{hPa}$ zonal winds (shading) and precipitation (contours). The E5SIT-Nord realistically simulates the 30-to-80-day eastward-propagating signals of planetary wavenumber 1 in circulation and wavenumber 1-3 in precipitation (Fig. 1b), which is consistent with the finding of Tseng et al. (2015). By contrast, the spectra of the E5SITTied simulation exhibit weaker signals in both circulation and precipitation over wavenumber 1 (Fig. 1c). The remaining parts of the Fig. 1d-f illustrate the eastward propagation of intraseasonal fluctuations with the lag-longitude diagram of precipitation and $10 \mathrm{~m}$ zonal winds regressed to the rainfall over the tropical Indian Ocean $\left(10^{\circ} \mathrm{S}-5^{\circ} \mathrm{N}, 75^{\circ} \mathrm{E}-100^{\circ}\right.$ E). The E5SIT-Nord simulation reproduces the distinctly observed eastward propagation, albeit slightly more slowly, of precipitation and surface winds (Fig. 1e), whereas the E5SIT-Tied simulation presents weak intraseasonal fluctuations in precipitation which is decoupled from zonal winds at the $\mathrm{MC}$, especially for the region of $120^{\circ}-150^{\circ} \mathrm{E}$ (Fig. 1f). 
Therefore, our analysis focuses on the convection-circulation coupling associated with $\mathrm{MJO}$ over the $\mathrm{MC}$ region. The mean states of zonal winds and precipitation rate are shown in Fig. S1, and maps of the ratio of the intraseasonal rainfall variability to the total rainfall variability are presented in Fig. S2. In line with the results of Tseng et al. (2015), the two model simulations have relatively similar mean states (Fig. S1). Both models simulate a higher ratio of intraseasonal rainfall variability to total variability than was observed, with the E5SIT-Nord model simulating the highest variability among the three datasets (Fig. S2b). By contrast, the variability simulated by the E5SIT-Tied model is weaker than what was observed (Fig. S2c).

While the contribution of the mean distribution of lowlevel moisture to MJO propagation has been emphasized in numerous studies (e.g., Jiang 2017), it appears not to be a major factor in our simulations, considering, as shown in Fig. S3a-c, the dryer mean state of the E5SIT-Nord simulation (relative to the E5SIT-Tied simulation), especially below $700 \mathrm{hPa}$ (Fig. S3d). An examination of model pattern correlations with ERA-Interim (from 1000 to $200 \mathrm{hPa}$ ) also reveals that both models effectively simulate distributions of horizonal moisture; the coefficient of correlation in the both runs exceeds 0.95 (Fig. S3e). Other studies have also shown that the vertical moisture distribution is not sufficient conditions for simulating MJO, and suggest the net vertical moistening associated with convective processes which coupled with large-scale environments are a key element for MJO simulation (Jiang et al. 2015; Peters et al. 2017). While the mean moisture pattern appears not to be the key differences between the two simulations, the convective processes that result in more accurate simulation of MJO propagation by the E5SIT-Nord are worthy of further exploration.

The autocorrelation analysis of daily rainfall of two runs and GPCP in Fig. S4 shows the coherence behaviors of convection in the tropics. In observations of GPCP, tropical rainfall signal is composed of strong alternating spells of wet and dry period (i.e. intermittency), which is shown by the reduction of autocorrelation function with lag days. Examining rainfall coherence can help understand the tendency of raining processes in climate models (Klingaman et al. 2017; Peters et al. 2017). Compared with GPCP and E5SIT-Tied, E5SIT-Tied shows weaker intermittency with tropical daily rainfall, especially for timescale longer than 5 days. This result suggests convection in E5SIT-Tied tends to be less organized. Such characteristics may hamper development of MJO organization in E5SIT-Tied run.

To examine the convection response associated with MJO circulations, the following analysis in Figs. 2, 3, 4 and Fig. $\mathrm{S} 5$ will focus on the region of $10^{\circ} \mathrm{S}-\mathrm{EQ}$ and $120^{\circ}-150^{\circ}$ E, spanning the area from the Banda Sea to the Maluku Islands and Java, where the strongest convective activities on intraseasonal scale in the MC region (Fig. S2). It is also the region where the MJO convective center often makes a southward detour when passing through the MC (Tseng et al. 2017). The evolution of convection activity of this region is closely coupled with MJO circulations during the MJO passage.

The evolution of essential atmospheric variables for the initiation and development of convection over the region of $10^{\circ} \mathrm{S}$-EQ and $120^{\circ}-150^{\circ} \mathrm{E}$ are plotted with respect to the MJO life cycle in Fig. 2. All variables underwent 20-to100-day band-pass filtering and are plotted against the simulated MJO phases, per the procedures of Wheeler and Hendon (2004). Figure $2 \mathrm{a}-\mathrm{c}$ shows the moisture convergence associated with the simulated MJO phases. The low-level convergence over the $\mathrm{MC}$ is the strongest below $850 \mathrm{hPa}$ in phases 1 and 2, and it continues shifting upward into the free troposphere starting from phase 3 (Fig. 2a). Both simulations capture the structure of low-level moisture convergence in the first two phases, but at smaller magnitudes. As shown in Fig. 2b, c, the simulated moisture convergence shifts to the free troposphere relatively quickly between phases 3 and 4 and becomes detached from the boundary layer. Moisture convergence is stronger and extends to higher levels in the E5SIT-Nord simulation than in the E5SIT-Tied simulation. The associated $Q_{1}$ and $Q_{2}$ over the MC region are also observable in Fig. 2d-f and g-i, respectively. E5SIT-Nord has a sharp contrast between convective heating and cooling during the MJO life cycle that is greater in amplitude than that in the E5SIT-Tied simulation and in the observation data. Consistent with the wave spectrum signals in Fig. 1, the magnitudes of $Q_{1}$ and $Q_{2}$ in the E5SIT-Tied simulation are substantially weaker than those in the E5SIT-Nord simulation. Notably, the observed $Q_{2}$ exhibits a distinct tilt, and both models simulate a rapid transition from the near-surface features to the deep convective structure in the middle troposphere. Figure $2 \mathrm{j}-1$ presents the evolution of the MSE profiles over the MC associated with MJO phases. The vertical development of the MSE, specifically through the upward transport of moisture from the near-surface to the low-level troposphere, results in conditions conducive to deep convection (Fig. 2j). The E5SIT-Nord simulates the gradual upward development of MSE with time, whereas the E5SIT-Tied (Fig. 2k, 1) simulates weak preconditioning with an unstable near-surface layer, followed by the sudden onset of high MSE and deep convection in mature phases. As noted by Tseng et al. (2015), this moistening process, characterized by the tilting of MSE, was only captured when the ECHAM5 was used in concert with the SIT.

As tropical convection has a multiscale nature, convective activities on other time scales can affect MJO-related convection development. Figure 3 presents the unfiltered $Q_{1}$ and $Q_{2}$ in eight MJO phases, corresponding to the intraseasonal ones shown in Fig. 2d-i. In the reanalysis, the $Q_{1}$ and $Q_{2}$ profiles (Fig. 3a, d) reveal the evolution of the convective 
(a) Moisture Con., Observations

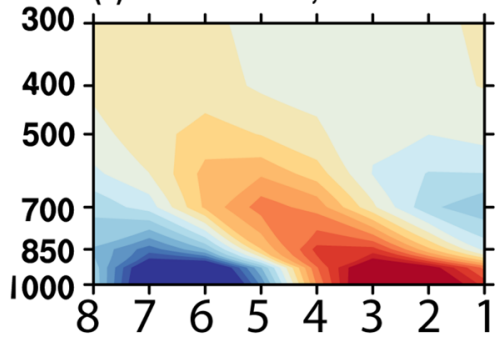

(d) Q1, Observations

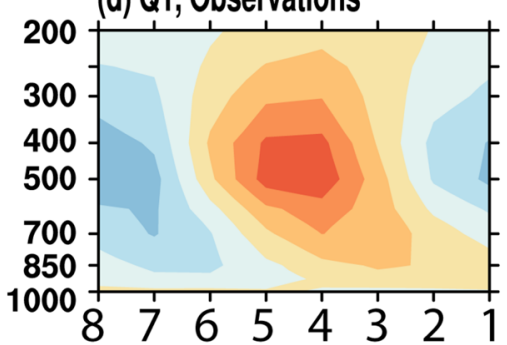

(g) Q2, Observations

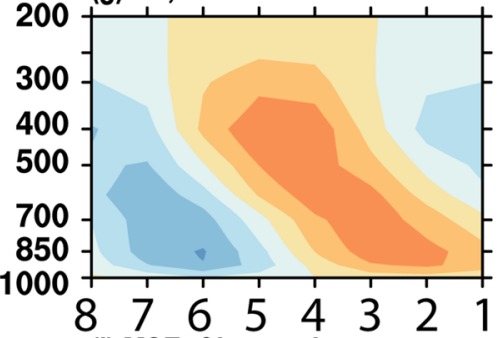
(j) MSE, Observations

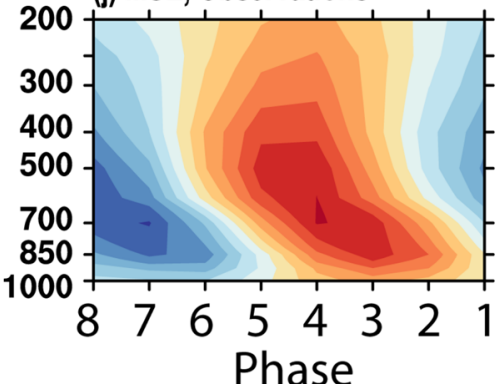

(b) Moisture Con., E5SIT-Nord

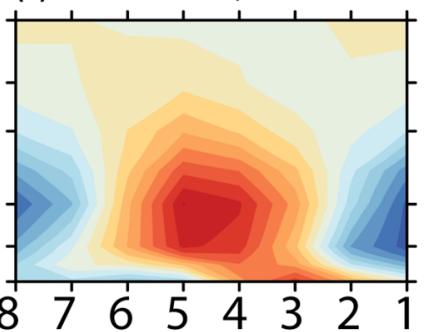

(e) Q1, E5SIT-Nord

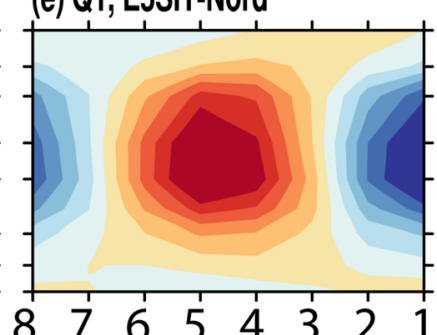

(h) Q2, E5SIT-Nord

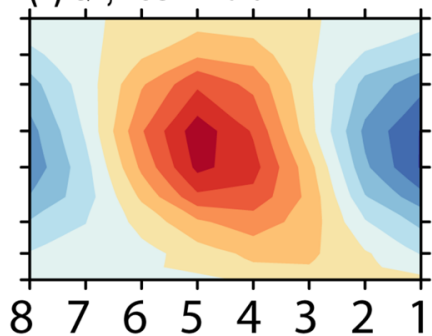

(k) MSE, E5SIT-Nord

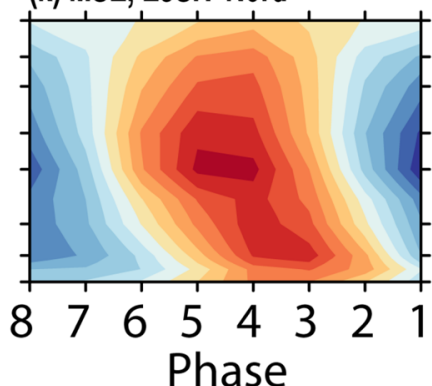

(c) Moisture Con., E5SIT-Tied

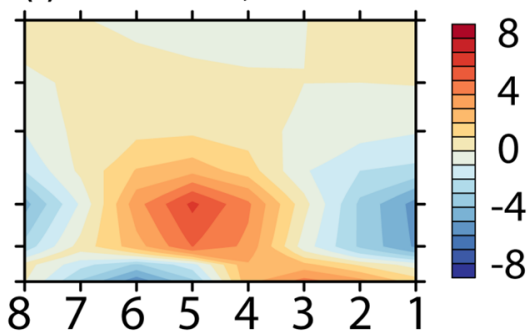

(f) Q1, E5SIT-Tied

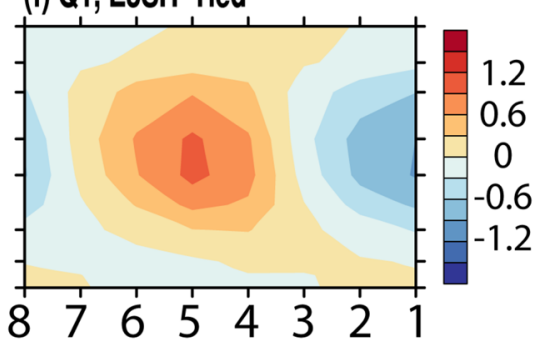

(i) Q2, E5SIT-Tied

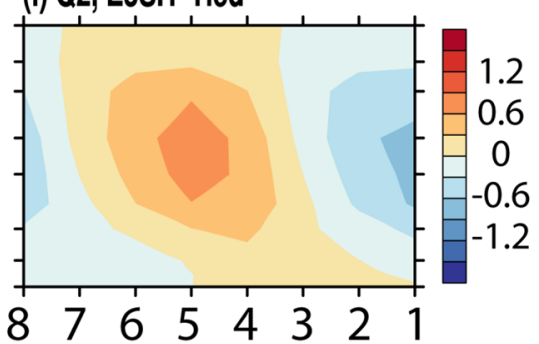

(l) MSE, E5SIT-Tied

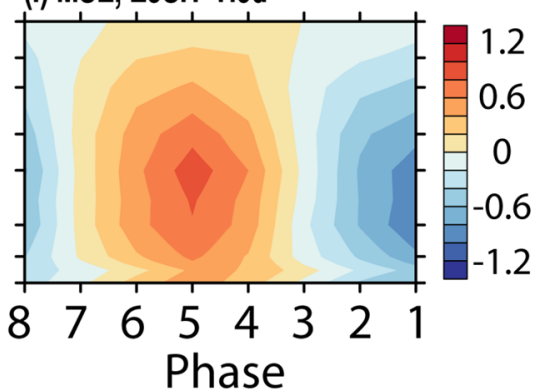

Fig. 2 Vertical profiles of intraseasonal anomalies (i.e., with 20-to-100-day band-pass filtering) in a-c moisture convergence $\left(10^{-6} \mathrm{~g} \mathrm{~kg}^{-1} \mathrm{~s}^{-1}\right)$; d-f the apparent heat source $\left(Q_{1} ; \mathrm{K}\right.$ day $\left.{ }^{-1}\right) ; \mathbf{g}-\mathbf{i}$ the apparent moisture sink $\left(Q_{2} ; \mathrm{K}\right.$ day $\left.^{-1}\right)$; and $\mathbf{j}-\mathbf{l}$ moist static energy $\left(10^{3} \mathrm{~J} \mathrm{~kg}^{-1} \mathrm{~s}^{-1}\right)$, with respect to Madden-Julian Oscillation phases

activities in the MJO, from the shallow convection in the earlier phases of phase 1-2 to the deep convection in the mature phases of phase $3-5$. Both models simulate heating or moistening over all phases that are stronger in magnitude than their observed counterparts. In the E5SIT-Nord experiment, the simulated $Q_{1}$ exhibits heating during the mature phases that is comparable to its observed counterpart; however, in phase 4, heating is greatly overestimated by as much as $4 \mathrm{~K} /$ day (Fig. 3b). By contrast, in the E5SITTied experiment, $Q_{1}$ heating persists from phase 3 to phase averaged over $10^{\circ} \mathrm{S}$-EQ, $120^{\circ}-150^{\circ} \mathrm{E}$. The variables are based on observational data from the ERA-Interim reanalysis, the NordengTiedtke scheme (E5SIT-Nord) simulation, and the Tiedtke scheme (E5SIT-Tied) simulation

8 (Fig. 3c). Notably, the mean $Q_{1}$ in the E5SIT-Tied simulation is larger than that in the E5SIT-Nord simulation when averaged over the entire MJO life cycle, the opposite of the $Q_{1}$ projection on the intraseasonal time scale (Fig. 2). Unlike the prominent $Q_{1}$ associated with MJO convective center in the observation data and the E5SIT-Nord simulation, the $Q_{1}$ heating in the E5SIT-Tied simulation persists from phases 1-8 of the MJO, demonstrating the maintenance of deep convection over the MC. This result and its relationship with lower simulation skill of MJO is explored in later sections. 


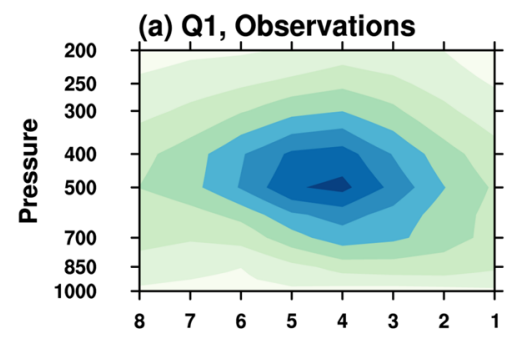

(d) Q2, Observations

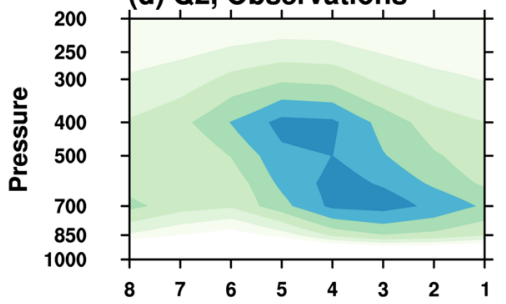

(b) Q1, E5SIT-Nord

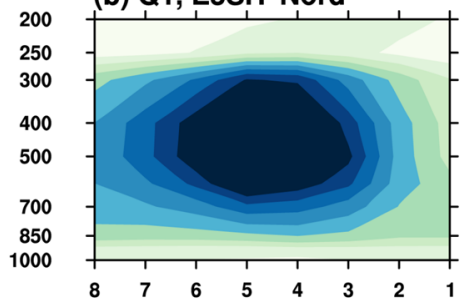

(e) Q2, E5SIT-Nord

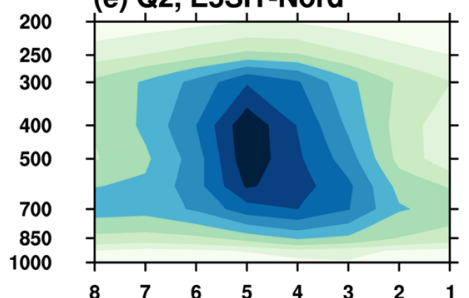

Phase

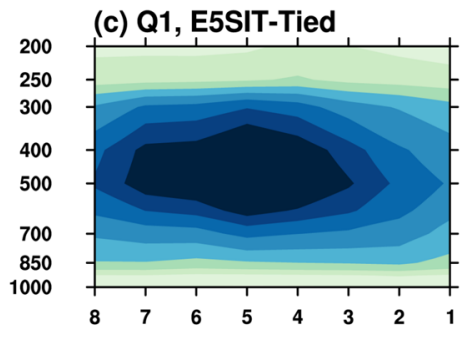

(f) Q2, E5SIT-Tied

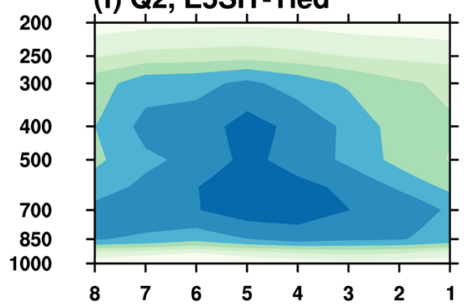

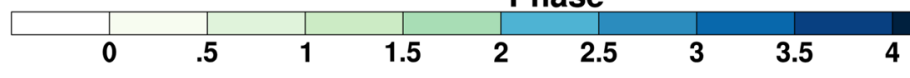

Fig. 3 Vertical profiles of the unfiltered composite field of the a-c apparent heat source $\left(Q_{1} ; \mathrm{K}\right.$ day $\left.^{-1}\right)$ and $\mathbf{d}-\mathbf{f}$ apparent moisture sink $\left(Q_{2} ; \mathrm{K} \mathrm{day}{ }^{-1}\right)$ plotted with respect to Madden-Julian Oscillation phases averaged over $10^{\circ} \mathrm{S}$-EQ, $120^{\circ}-150^{\circ} \mathrm{E}$. The data are from the ERA-Interim reanalysis, Nordeng-Tiedtke scheme (E5SIT-Nord) simulation, and Tiedtke scheme (E5SIT-Tied) simulation (a) Observations, phase 1

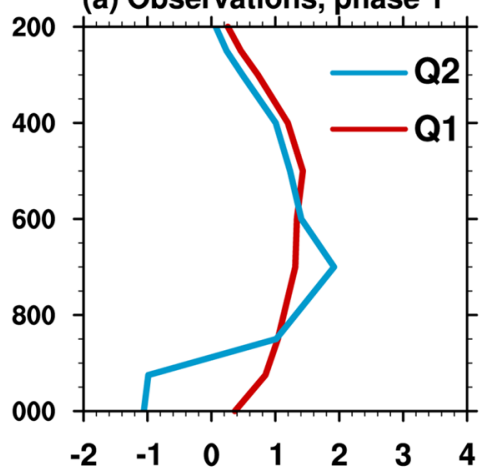

(d) Observations, phase 2

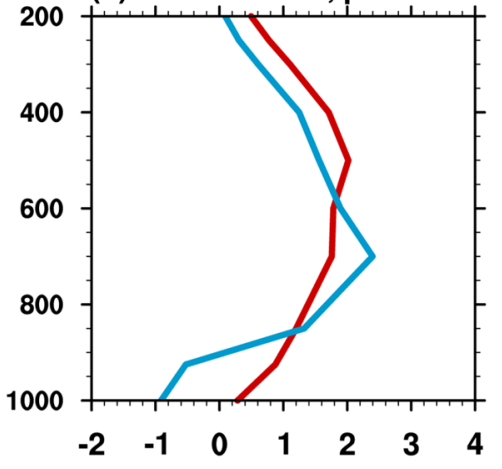

(b) E5SIT-Nord, phase 1

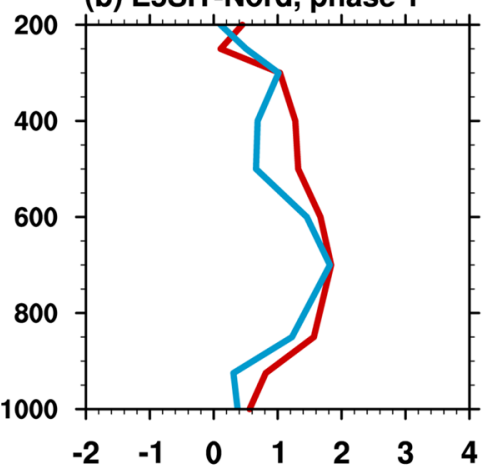

(e) E5SIT-Nord, phase 2

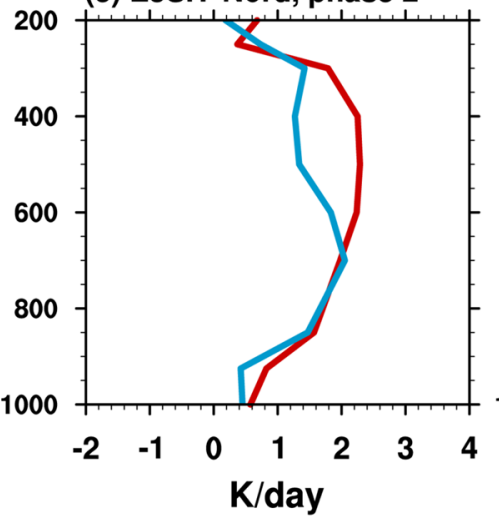

(c) E5SIT-Tied, phase 1

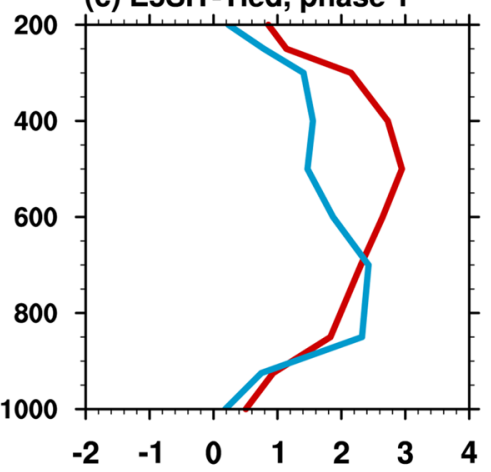

(f) E5SIT-Tied, phase 2

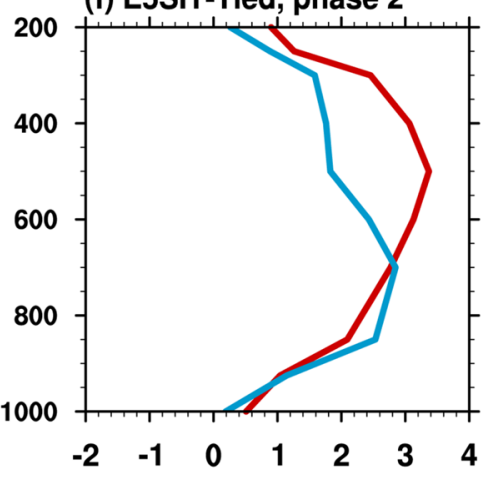

Fig. 4 Vertical profiles of apparent heat source $\left(Q_{1} ; \mathrm{K} \mathrm{day}^{-1}\right.$; red lines) and apparent moisture sink $\left(Q_{2} ; \mathrm{K} \mathrm{day}^{-1}\right.$; blue lines) with respect to Madden-Julian Oscillation phases averaged over $10^{\circ} \mathrm{S}$-EQ and $120^{\circ}-150^{\circ} \mathrm{E}$ for $\mathbf{a}-\mathbf{c}$ phase 1 and $\mathbf{d}-\mathbf{f}$ phase 2 . The data are from the ERA-Interim reanalysis, Nordeng-Tiedtke scheme (E5SIT-Nord) simulation, and Tiedtke scheme (E5SIT-Tied) simulation 
We focus on the convection activities over the MC during phases 1 and 2 of the MJO, when the deep convection center is over the Indian Ocean. Figure 4 shows the $Q_{1} / Q_{2}$ profiles over $10^{\circ} \mathrm{S}-\mathrm{EQ}$ and $120^{\circ}-150^{\circ} \mathrm{E}$ during these phases in the ERA-Interim analysis, in the E5SIT-Nord simulation, and in the E5SIT-Tied simulation. In phase 1, the peak of $Q_{1}$ in the reanalysis exhibits relatively homogeneous heating at a maximum rate of $1 \mathrm{~K} /$ day, suggesting a relative clear atmosphere with radiative heating and shallow convective heating dominate $Q_{1}$ (red line in Fig. $4 \mathrm{a}$ ). The $Q_{2}$ profile peaks at $700 \mathrm{hPa}$, indicating drying within the planetary boundary layer (PBL) and moistening in the lower troposphere. Such profiles suggest that during this period, moisture is transported from the PBL to the lower troposphere over the MC (blue line in Fig. 4a) through bottom-heavy convection. In the E5SIT-Nord, during phase 1 , the $Q_{1}$ value peaks at approximately $700 \mathrm{hPa}$, with a bottom-heavy profile. At the same time, the $Q_{1}$ and $Q_{2}$ peaks correspond to each other, implying that convection is shallow at this point, mainly moistening the low-level troposphere (Fig. 4b). By contrast, in the E5SIT-Tied simulation, the $Q_{1}$ and $Q_{2}$ profiles peak near 500 and $700 \mathrm{hPa}$, respectively, suggesting deep, intense convection over the MC (Fig. 4c). As shown in Fig. 4d-f, deep convective heating at approximately $500 \mathrm{hPa}$ is higher in phase 2 in both the ERA-Interim analysis and the two simulations. As is the case in phase 1, heating is deeper and more intense in the E5SIT-Tied simulation than in the E5SIT-Nord simulation or the ERA-Interim reanalysis.

Figure S5, which presents an analysis of the MSE budget over the region of $10^{\circ} \mathrm{S}-\mathrm{EQ}, 120^{\circ}-150^{\circ} \mathrm{E}$ during phases 1 and 2, elucidates the differences between the two simulations and the ERA-Interim reanalysis. Among the budget terms in E5SIT-Nord, those concerning horizontal and vertical advection terms contribute positively to the tendency term, which is partially cancelled out by longwave radiation. By contrast, the E5SIT-Tied simulates less vertical advection and very weak negative horizontal advection. The cancellation by longwave radiation results in an almost negligible tendency. The principal differences between the E5SIT-Nord and E5SIT-Tied simulations appears to be in the horizontal advection term and vertical advection terms, which further result in the poorer ability of E5SIT-Tied to simulate the propagation of the MJO. In phase 2, differences in horizontal advection that become the dominant term in the MSE budget increase as convection moves closer to the MC (Fig. S5b). Although the budget terms computed from the reanalysis have large MSE residuals, as in previous studies (Kiranmayi and Maloney 2011; Jiang 2017), vertical and horizontal advection likely to be crucial contributors to MSE tendency; this is highly consistent with that calculated from the E5SITNord simulation.
Figure 5 shows the MJO structures in phases 1 and 2, with overturning circulation (vectors), $Q_{1}$ (shading), and moisture convergence (green contours). The horizontal maps represent the precipitation and sea level pressure, respectively (bottom panel in Fig. 5). In phases 1, the MJO convective center is located over the central Indian Ocean (around $80^{\circ}-90^{\circ} \mathrm{E}$ ), with an upward motion driven by deep convective heating. To the east, subsidence is induced above most of the $\mathrm{MC}\left(120^{\circ}-150^{\circ} \mathrm{E}\right)$ with lowlevel moisture convergence developed below $850 \mathrm{hPa}$ (Fig. 5a). During this phase, E5SIT-Nord simulates strong subsidence and low-level moisture convergence over the $\mathrm{MC}$ and low-level easterlies over the eastern Indian Ocean (Fig. 5b). By contrast, E5SIT-Tied simulates very weak subsidence and easterlies over the MC and the eastern Indian Ocean, respectively, indicating weak convective responses to MJO-scale circulations (Fig. 5c). In phase 2, MJO convection propagates eastward with more intense precipitation covering Indian Ocean and Sumatra island. Both subsidence and Kelvin-wave structure are enhanced in response to stronger convective activities (Fig. 5d). Similar to the phase 1, E5SIT-Tied exhibits much weaker deep convective activities, weaker overturning structure, and little eastward propagation compared with observations and E5SIT-Nord (Fig. 5d-f).

To further visualize the coupling of moisture buildup and the MJO over the MC, we examine the large-scale circulation patterns and thermodynamics during periods when the moisture buildup over the MC is the most substantial. We first define intraseasonal moisture buildup by characterizing the duration of moisture residence in the tropospheric column before removal through rain ( $\left[\int_{p_{B}}^{p_{T}} q d p\right.$ ]$/[P])$ over the entire $\mathrm{MC}\left(10^{\circ} \mathrm{S}-10^{\circ} \mathrm{N}, 120^{\circ}-150^{\circ} \mathrm{E}\right)$, where [.] is the intraseasonal filtering, $q$ is moisture, $P$ is the rain rate, $p_{T}$ is the pressure at the cloud top, and $p_{B}$ is the pressure at the cloud bottom. The normalized convective time scale over the southern MC are calculated with respect to the lag-regressed fields to the series 1 of RMM (RMM1) index with ERA-Interim and two model runs in Figure S6. The RMM1 is defined as the PC of the leading EOF mode representing the coupled structure of convection and circulations when the convection center of MJO occurs at the longitude of MC (Wheeler and Hendon 2004). In ERA-Interim, convective time scale over the MC increases gradually from phase 1 (i.e., -20 days), reaching the maximum in phase 2 (i.e., -12 days; green line in Fig. S6), indicating moisture buildup peaks around 10 days before the deep convection activity on day 0 and under dominant shallow convection (from $Q_{1} / Q_{2}$ in Fig. 2). Figure 6 presents the regressed structure of the $Q_{2}$, MSE, and wind fields on the time series of accumulation of Fig. S6 in the ERA-Interim reanalysis, E5SIT-Nord simulation, 


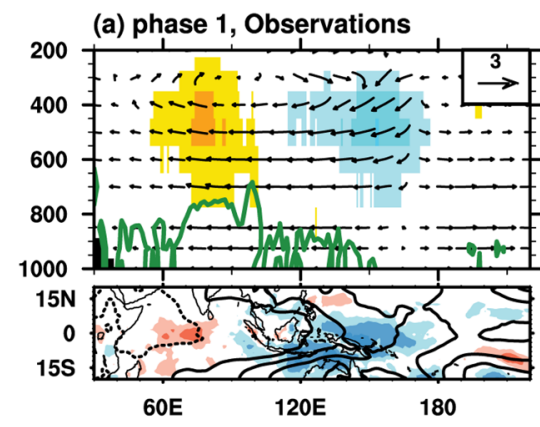

(d) phase 2, Observations

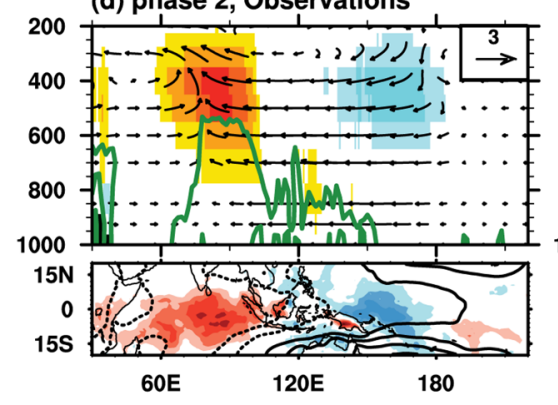

(b) phase 1, E5SIT-Nord

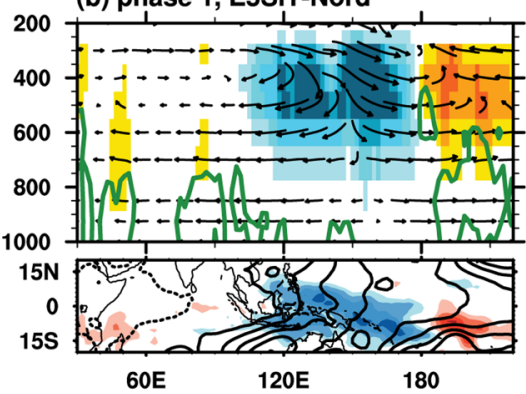

(e) phase 2, E5SIT-Nord

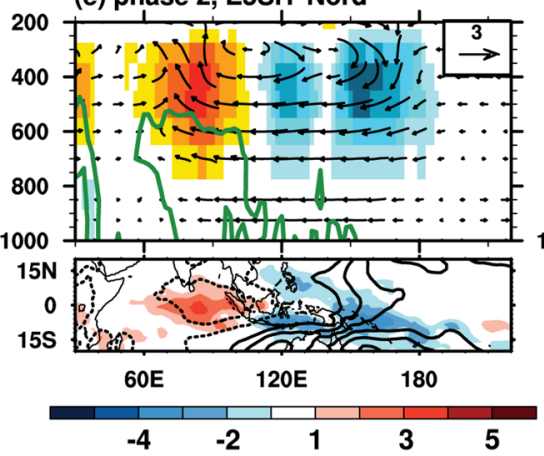

(c) phase 1, E5SIT-Tied

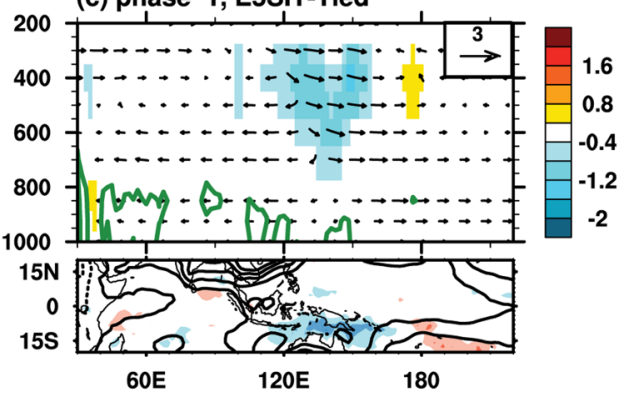

(f) phase 2, E5SIT-Tied

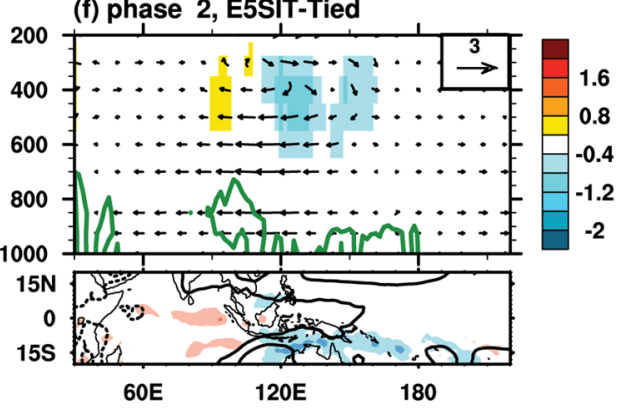

Fig. 5 Structure of simulated Madden-Julian Oscillation (MJO) during a-c phase 1 and d-e phase 2. The longitude-height cross-sections (averaged over $10^{\circ} \mathrm{S}-\mathrm{EQ}$ ) of the MJO-scaled wind circulation (vector, $u$ : $\mathrm{ms}^{-1}$, omega: $10^{-2} \mathrm{~Pa} \mathrm{~s}^{-1}$ ), $Q_{1}$ (shaded area; $\mathrm{K} \mathrm{day}^{-1}$ ), and the horizontal moisture convergence (green contour; the contour lines are shown only in 0 and $\left.3 ; 10^{-6} \mathrm{~g} \mathrm{~kg}^{-1} \mathrm{~s}^{-1}\right)$ in the a, $\mathbf{d}$ ERA-Interim rea- nalysis; b, e Nordeng-Tiedtke scheme (E5SIT-Nord) simulation, and c, $\mathbf{f}$ Tiedtke scheme (E5SIT-Tied) simulation. The contour interval of the moisture convergence is $8 \times 10^{-6} \mathrm{~g} \mathrm{~kg}^{-1} \mathrm{~s}^{-1}$. The solid line is positive. Precipitation (shaded area; $\mathrm{mm} \mathrm{day}^{-1}$ ) and sea level pressure (contour; $\mathrm{hPa}$ ). The contour interval is $30 \mathrm{hPa}$. The dashed line is negative (a) Obervations

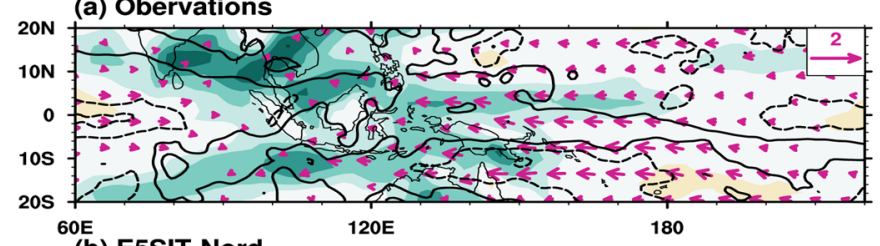

(b) E5SIT-Nord

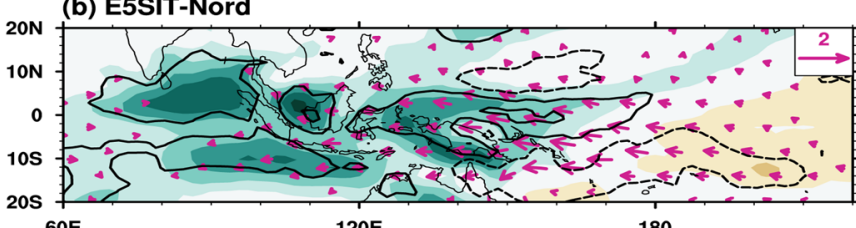

(c) E5SIT-Tied

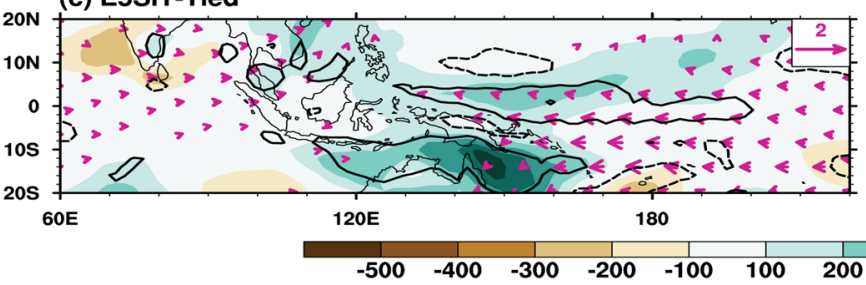

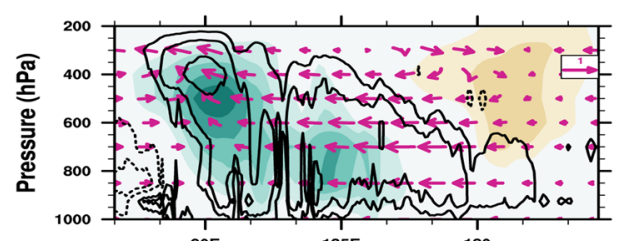
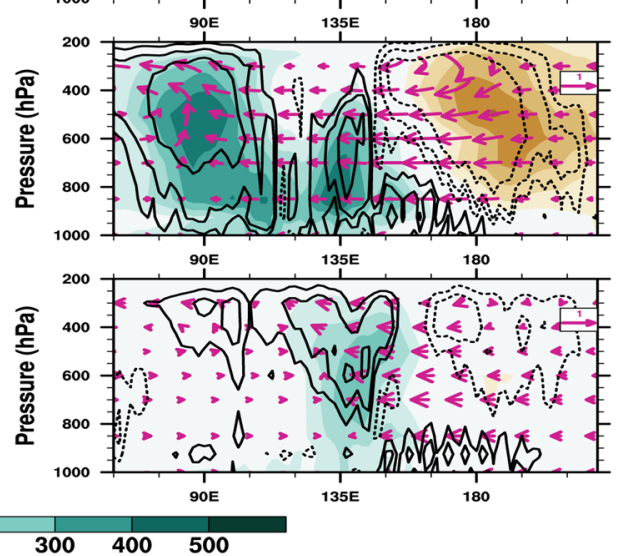

Fig. 6 Regressed structure of circulation patterns, the apparent moisture sink $\left(Q_{2}\right)$, and moist static energy (MSE) on intraseasonal convective time scale (shown in Fig.S6) in the a ERA-Interim reanalysis, b Nordeng-Tiedtke scheme (E5SIT-Nord) simulation, and c Tiedtke scheme (E5SIT-Tied) simulation. The MSE $\left(\mathrm{J} \mathrm{kg}^{-1} \mathrm{~s}^{-1}\right)$ is shown in the shaded area, $Q_{2}\left(\mathrm{~K} \mathrm{day}^{-1}\right)$ is shown in black contours, and the circulation winds $\left(\mathrm{ms}^{-1}\right)$ are shown as vectors where the value less than 0.1 is not shown. The left panel shows the horizontal maps of $850 \mathrm{hPa}$ fields, and the right panel shows the height-longitude crosssections averaged over $10^{\circ} \mathrm{S}-\mathrm{EQ}$. The black contour intervals in the left and right panels are 0.2 and 0.1 , respectively 
Fig. 7 Vertical profiles of $Q_{2}$ $\left(\mathrm{K} \mathrm{day}^{-1}\right)$ composited from categories of rainfall intensity $(\mathrm{mm}$ day $^{-1}$ ) over the tropical oceanic regions covering $10^{\circ} \mathrm{S}-5^{\circ} \mathrm{N}$, $80^{\circ}-160^{\circ} \mathrm{E}$ simulated by the a Nordeng-Tiedtke scheme (E5SIT-Nord) and b Tiedtke scheme (E5SIT-Tied); $\mathbf{c}$ shows the differences between the two simulations. Only the ocean grid is calculated (a) E5SIT-Nord

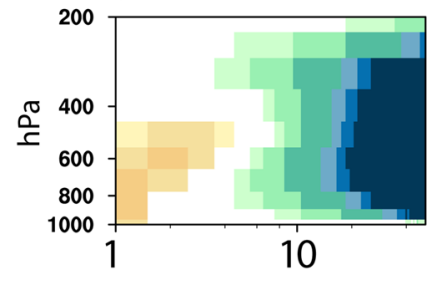

(b) E5SIT-Tied

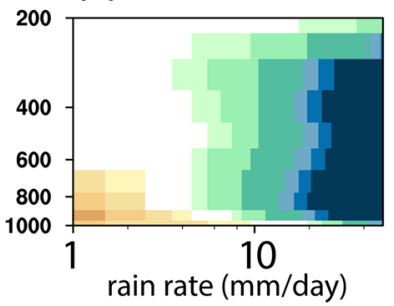

(c) Difference

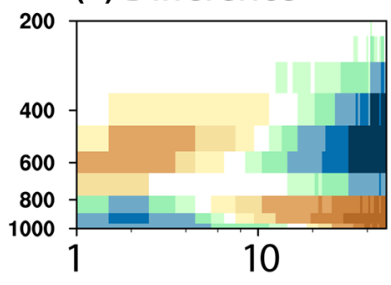

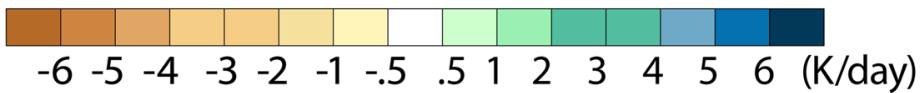

and E5SIT-Tied simulation. A distinct feature of MJO with convective center at the Indian Ocean and dynamical responses are shown in both the reanalysis and the E5SITNord simulation. Notably, a realistic structure similar to Kelvin waves with two off-equatorial MSE maxima over the eastern Indian Ocean under strong easterlies at the equatorial MC is present only in the E5SIT-Nord simulation. On the other hand, the missing of the deep convection signal over the east Indian Ocean and west MC are shown in the E5SIT-Tied run (Fig. 6c). Also in reanalysis and E5SIT-Nord, the zonal-height cross-section exhibits a tilted structure of well-collocated MSE and $Q_{2}$, which depicts a MJO structure in the developing phase (at approximately phase 2) (Fig. 6a, b). The tilted structure involves deep convection near $90^{\circ} \mathrm{E}$, relatively shallow convection at $120^{\circ} \mathrm{E}$, and low-level moistening by convective processes between $120^{\circ} \mathrm{E}$ and $150^{\circ} \mathrm{E}$. The $Q_{2}$ tilt in the E5SIT-Nord is more rapid than that in the ERA-Interim reanalysis (as indicated by black contours in the right panels of Fig. 6a, b). Such westward-tilting vertical structures have been identified in numerous observational studies (Kiladis et al. 2005; Kim et al. 2009; Tseng et al. 2015; Jiang et al. 2015). By contrast, the E5SIT-Tied simulation reveals local deep convection and a MSE maximum over the MC $\left(120^{\circ}-150^{\circ} \mathrm{E}\right)$, implying the MSE anomaly over MC couples only with local convection activity, not with the large-scale circulation patterns that are further linked to deep convection in the Indian Ocean. The meridional cross-section over $120^{\circ}-150^{\circ} \mathrm{E}$ also indicates the anomalies in the deep $Q_{2}$ and the MSE over the MC in the E5SITTied simulation (Fig. S7). By contrast, both the E5SITNord simulation and the ERA-Interim reanalysis exhibit a shallower $Q_{2}$ and MSE structure, with the maximum at approximately $800 \mathrm{hPa}$. As in the ERA-Interim reanalysis and the E5SIT-Nord simulation, this is a precondition for the development of deep convection over the MC and the eastward propagation of the MJO when convection is still over the Indian Ocean.

The characteristics of convective moistening (i.e., $Q_{2}$ ) to rainfall categories and SST are presented as follows to investigate the impacts of convective process on environments.
We especially focused on oceanic convection in our analysis to take the advantage of ECHAM5-SIT model setup in better representation of the atmosphere-ocean coupling. Also, many studies have found the land convection over the MC competes moisture with MJO-scale convection, having a blocking effect rather than supportive effect for MJO propagation (Hagos et al. 2016; Ahn et al. 2020a). Examining interactions between land convective activity and the MJO propagation is beyond the scope of this study and will be a great topic for future study. Figure 7 shows the $Q_{2}$ profiles stratified by the daily rain rate averaged over the tropical oceans $\left(10^{\circ} \mathrm{S}-5^{\circ} \mathrm{N}, 80^{\circ}-160^{\circ} \mathrm{E}\right)$ in the two model runs and their differences. For low rain rates (1-10 $\mathrm{mm} /$ day), the E5SIT-Nord simulates a more bottom-heavy $Q_{2}$ profile than the E5SIT-Tied does, transporting moistening from PBL into the low troposphere. For high rain rates, E5SIT-Nord simulates stronger drying (more latent heating) in the middle troposphere associated with strong convective activity, compared with E5SIT-Tied. The two characteristics (i.e., stronger low-level moistening and stronger deep drying) of the E5SIT-Nord simulation help create more favorable environmental conditions for the propagation of the MJO. Figure 8 shows the percentage of rainfall occurrences stratified with respect to SST and rainfall intensity. The highest rainfall is noted between 28 and $30{ }^{\circ} \mathrm{C}$ (Fig. 8a, b) in both the observation and the E5SIT-Nord simulation. By contrast, the E5SIT-Tied simulates more frequent rainfall when the SST is higher than $30^{\circ} \mathrm{C}$, suggesting the E5SIT-Tied tends to be overresponsive to high SST, producing an excessive amount of local convective rainfall (Fig. 8c).

\section{Case study on the MJO involving two CPSs}

The difference in the representation of convection-circulation coupling in the two simulations may not be directly ascribable to the representation of the convective processes in the CPS. To examine the relationship between the instantaneous convective response to the MJO circulation and convection-circulation biases found in climate runs, we conduct a simulation of an MJO case, using initial conditions from 

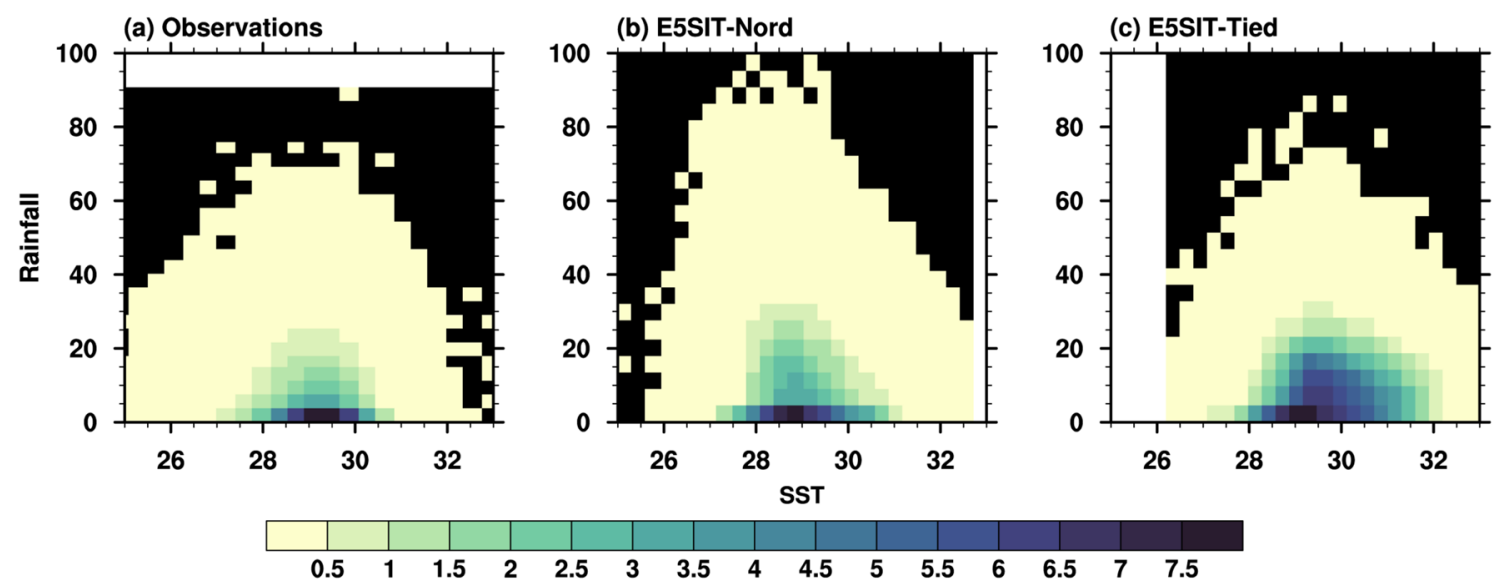

Fig. 8 Distribution of occurrence of daily rainfall with respect to rainfall intensity and sea surface temperature (SST). The categories were ranked into bins over the tropical oceanic regions covering $10^{\circ}$ $\mathrm{S}-5^{\circ} \mathrm{N}, 80^{\circ}-160^{\circ}$ E simulated by the a Observations, b Nordeng-

the ERA-Interim reanalysis. Having the setup of the two schemes, the simulation is initiated at the start point of October 31, 2011, when a well-developed MJO is observed over the Indian Ocean. The two experiments are then integrated for 3 days and analyzed for their differences in days 1 and 2. This setup is designed to compare the response of moist convection processes and ensure that the large-scale circulation patterns remain close to the initial conditions. The diagnostics are useful for understanding the biases caused by the model representation of convective processes from diurnal to interannual time scales (Ma et al. 2021).

Figure 9 shows the differences in circulation patterns and sea level pressure between the two simulations, in the form of a height-longitude cross-section and horizontal maps, on the first and second days after model initiation. On day 1, the convection center of the MJO is over the tropical Indian Ocean (near $90^{\circ} \mathrm{E}$ ), with weak subsidence in the east over the MC and the western Pacific. After 1-day integration, the E5SIT-Nord simulation produces (1) stronger upward motion associated with convective center at $90^{\circ} \mathrm{E}$ and (2) a stronger basin-wide subsidence coupled with positive anomaly of sea level pressure over the MC and the western Pacific from $120^{\circ} \mathrm{E}$ to $180^{\circ} \mathrm{E}$ (Fig. 9a). Only spotty upward motion can be found over islands of New Guinea and Celebes as increased solar radiation under subsidence creates favored environments for local land convection (Fig. 9a). In accompany with circulations, stronger convective drying represented by Q2 in E5SIT-Nord at the convective center compared with E5SIT-Tied (shown as black contours in Fig. 9a). To the east of deep convective center of MJO, the convection over the MC in the E5SIT-Nord simulation in response to the subsidence is much shallower than that in the E5SIT-Tied simulation, especially over the Borneo, near $120^{\circ} \mathrm{E}$ (black contours in Fig. 9a). Notably, in the E5SIT-Nord simulation,
Tiedtke scheme (E5SIT-Nord) and c Tiedtke scheme (E5SIT-Tied). There are 25 bins for both rainfall and SST. Only the ocean grid is calculated

more moisture is available in the lower troposphere and less moisture is available in the PBL below $850 \mathrm{hPa}$ over the MC and the western Pacific (represented by MSE; shading in Fig. 9a); this is indicative of stronger shallow convection that helps create a favorable environment for deep convection. In the meantime, the E5SIT-Nord presents a horizontal structure similar to Kelvin waves which appears in the zonal dipole of sea level pressure, forming easterlies over the equatorial MC and the eastern equatorial Indian Ocean (bottom panel in Fig. 9a). This implies that the deep convection heating in the E5SIT-Nord simulation produces stronger dynamic responses than E5SIT-Tied simulation.

On day 2, when the convective center moves toward the western MC, different responses attributable to the two schemes become more substantial. Relative to the E5SITTied simulation, the stronger upward motion at the convective center of the E5SIT-Nord simulation leads to stronger subsidence and enhanced tropical easterlies extending to the western Pacific (arrows in the bottom panel of Fig. 9b). Notably, a more prominent structure of Kelvin waves appears in response to both winds and sea level pressure (near $130^{\circ} \mathrm{E}, 10^{\circ} \mathrm{N}$; bottom panel of Fig. 9b). In addition to the enhanced easterlies, the meridional winds at the north side of the equator also become stronger, which in turn enhances low-level convergence at the equator. Accompanying the vertical transport of shallow convection, more moisture accumulates over the low levels between 800 and $500 \mathrm{hPa}$ in the E5SIT-Nord simulation, providing conditions more conductive for MJO propagation, as mentioned in other studies (Kiranmayi and Maloney 2011; Adames 2017; Maloney et al. 2019). Consistent with the findings on climatological MJO composites in Fig. 7, these features also suggest that E5SIT-Nord can simulate stronger convective heating in the 


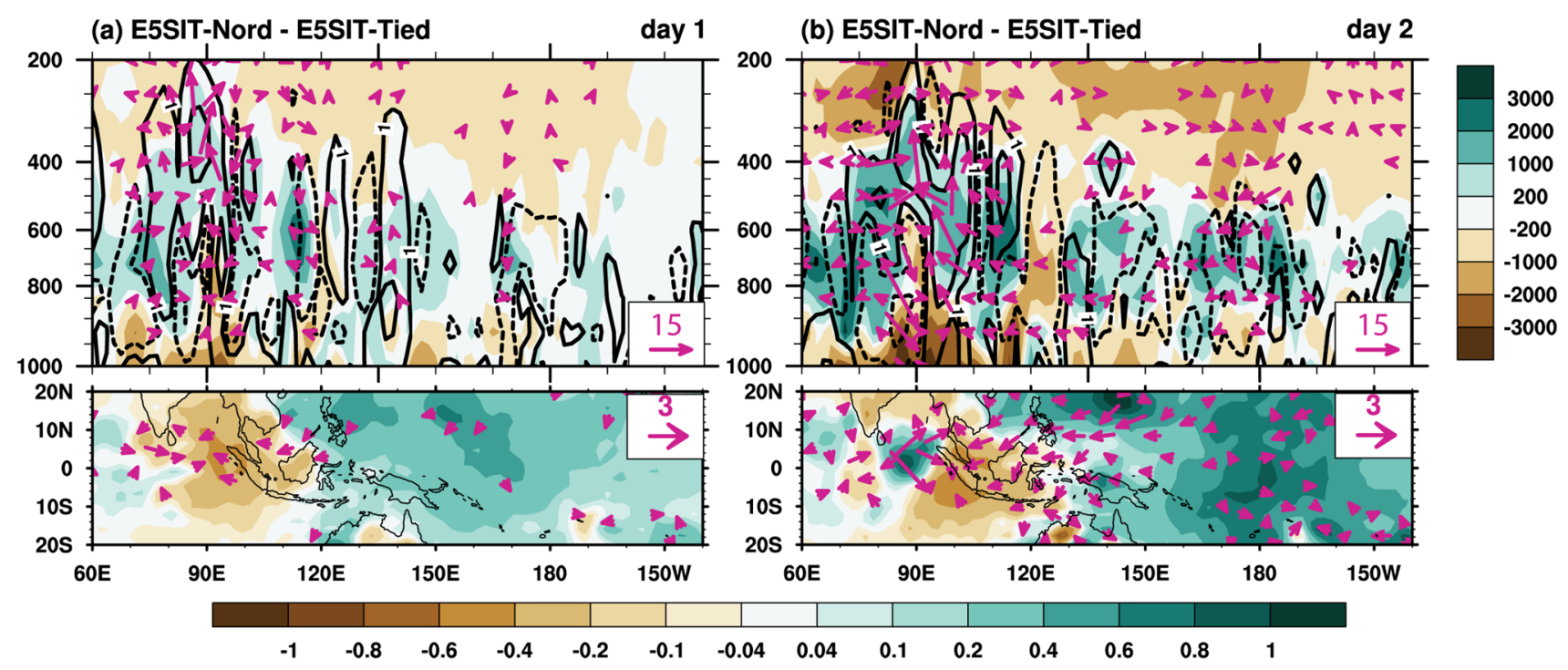

Fig. 9 Differences in circulation patterns and sea level pressure between the Nordeng-Tiedtke scheme (E5SIT-Nord) and Tiedtke scheme (E5SIT-Tied) simulations in the form of height-longitude cross-sections over the equator and horizontal maps on a day 1 and b day 2 after model initiation. The upper panel shows MSE (shaded area; $\mathrm{J} \mathrm{kg}^{-1} \mathrm{~s}^{-1}$ ), $Q_{2}$ (Contours; $\mathrm{K}$ day $^{-1}$, interval is $-5,-1,1,5$ ), and circulations $\left(\mathrm{u}, \mathrm{m} / \mathrm{s}\right.$; omega, $10^{-2} \mathrm{~Pa} / \mathrm{s}$; with omissions for $\mathrm{u}$ wind velocity under 3 ). The lower panel shows the sea level pressure (shaded area; $\mathrm{hPa}$ ), and the surface winds $(\mathrm{m} / \mathrm{s}$ for both $\mathrm{u}$ and $\mathrm{v}$, with omissions for total wind speed under $0.8 \mathrm{~m} / \mathrm{s}$ )

\section{Nordeng}

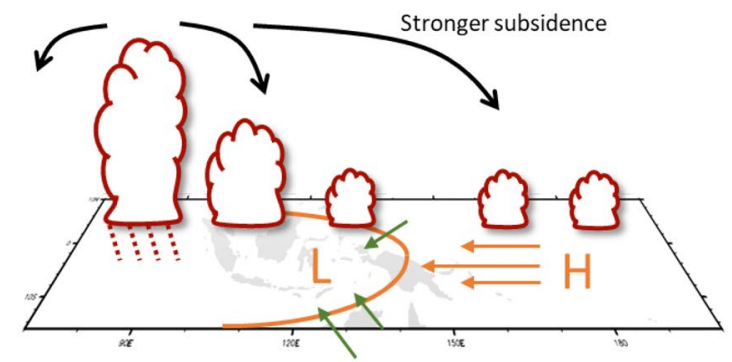

Fig. 10 Schematic of convection-circulation coupling in the Madden-Julian Oscillation based on the analysis of the Nordeng-Tiedtke and Tiedtke scheme simulations during MJO development (over

deep convection regime and greater moistening in the shallow convection regime than the E5SIT-Tied can.

\section{Discussion}

The comparison of the two model simulations against observational data revealed the importance of proper coupling between convection and large-scale circulation patterns in climate models to the realistic simulation of the MJO. In the E5SIT-Tied simulation, the persistent but fleeting period of deep convection dries out the moisture over the MC even during MJO development, resulting in conditions that are

\section{Tiedtke}

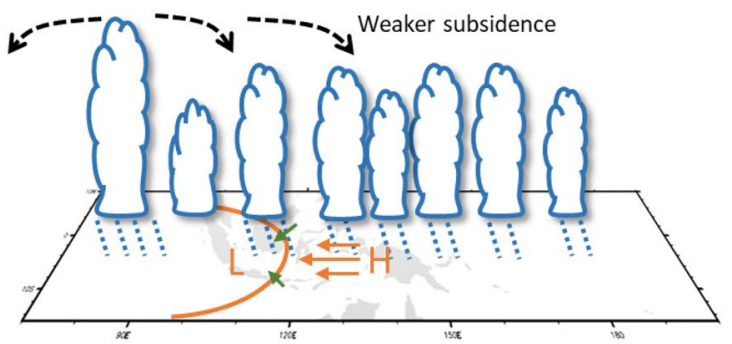

phases 1 and 2). Convection is represented as clouds; convectioninduced subsidence and horizontal wind fields are shown as black arrows and color arrows, respectively

less favorable for MJO propagation. By contrast, E5SITNord better simulates the moisture buildup over the MC during MJO development, facilitating the propagation of the MJO over deep convective regions. Figure 10 presents the differences between the model simulations with regard to the convection-circulation coupling during MJO development.

Based on our results, we suggest two aspects of convection-circulation coupling that are vital to improving simulations of MJO propagation: (1) the ability to generate deep convective heating and induce subsidence to the east of convective center and (2) the ability to induce moisture buildup in the subsidence region and create an environment that is conducive to the later development of deep convection. 
During the early phases of the MJO, when the convective center is located in the Indian Ocean, deep heating induces Kelvin-wave-like perturbations (e.g., easterlies and lowpressure anomalies) that extend eastward with a subsidence branch to the MC and the western Pacific (Milliff and Madden 1996; Hendon and Salby 1996; Cravatte et al. 2003; Kiladis et al. 2005). If the deep convective heating is only weakly simulated, the induced subsidence becomes too weak to suppress the deep convection over the MC region where the SST is high. The preconditioning for the propagation of the MJO to the MC also requires the buildup of low-level moisture, which is often caused by the moistening effect of shallow convection (from the transport of moisture from the PBL). Such moisture buildup is often controlled by the representation of moist convection in climate models, especially in the determination of the type of convection and the associated heating/moistening. When the convection in the model is overly sensitive to high SST, convection can be frequently triggered, depleting moisture and precluding the realistic simulation of the moistening process over the MC when MJO is approaching. Our analysis also suggests that climate models must be capable of producing the contrast between light and intense rainfall events-that is, to simulate deep heating with intense rainfall and shallow moistening with light rainfall. E5SIT-Tied is more likely to present weaker and more frequent convection than its observed counterpart and also lighter than that simulated by E5SIT-Nord. Such a tendency results in a more stable atmosphere, which makes it more challenging to model the convection-circulation coupling with MJO in E5SIT-Tied.

Numerous studies have indicated that the design of convection schemes is essential to accurately simulating the MJO, including the sensitivity of CPS to the tropospheric moisture by entrainment or detrainment (Hannah and Maloney 2014), momentum transport (Wu et al. 2007; Miyakawa et al. 2012), microphysical processes, intensity closure (Zhang and Mu 2005; Peters et al. 2017), triggering (Peters et al. 2017), the representation of stratiform convection (Fu and Wang 2009), and shallow convection (Zhang and Song 2009). The discrepancies between simulations observed in the present study could be attributable to various differences in the design of the Nordeng-Tiedtke and Tiedtke schemes, such as the sensitivity to tropospheric humidity caused by entrainment design (Möbis and Stevens 2012). We take a diagnostic approach, interpreting these differences in a context of convection-circulation coupling. To ensure the successful simulation of MJO propagation, the model representations of convection must be consistent. The similarity in the biases concerning convection-circulation coupling as observed in both the case study and the climate simulations suggests that biases in fast convective response can further induce intraseasonal biases. To improve the simulation of intraseasonal variability by better representing convection-circulation coupling, it is necessary to carefully design responses of CPS to environmental characteristics, such as wind, humidity, and SST. The process-based diagnostic used in the present study is useful for understanding model performance with regard to convection-circulation coupling and can also be used to evaluate designs of CPS for MJO simulation.

While our study focuses on how the convection responds to MJO-scale circulations, air-sea coupling is a key process to enhance MJO simulations in the ECAHM5 in previous studies. Tseng et al. (2015) has found by coupling SIT to ECHAM5, i.e. E5SIT-Nord setup in our study, the model can better resolve variation of upper ocean temperature structure, especially in the warm layer from the surface to $10 \mathrm{~m}$. When MJO moves to Indian Ocean, its convection center induces subsidence to its east leading edge, causing clear sky condition and weakening surface winds there. With SIT, surface warm layer is resolved and warmed due to more incident solar radiation associated with the enhanced subsidence and weaker evaporative cooling due to weakened winds. The warmer SST ahead of the MJO further destabilizes the boundary layer and enhances frictional convergence to help organize and strengthen deep convection, which is hypothesized to lead to a more realistic eastward-propagating MJO. More vigorous atmosphere-ocean interaction can thus strengthen intraseasonal variations in both SST and atmospheric circulation. Our preliminary study has shown that with AGCM setup the ECHAM5 models hardly capture the eastward propagating intraseasonal signals, which hampers further study of convection response to MJO-scale circulations (Fig. S8).

Although we focus on the CPS, MJO-related convection-circulation coupling actually depends on the combined effects of moist convection designs, including shallow convection, the PBL, and the parameterization of air-sea interaction. For example, with regard to application in models derived from the Community Atmosphere Model 2, Liu et al. (2005) concluded that the Tiedtke scheme outperforms the Nordeng-Tiedtke scheme because of its ability to trigger convection with low-level convergence. Considering that the ECHAM5 used here had different PBL schemes and shallow convection schemes from Community Atmosphere Model 2, the moisture buildup processes that are involved are likely to differ substantially. The simulations in the present study considered air-sea coupling, which, according to DeMott et al. (2019), are crucial contributors to the low-level moistening observed in successful MJO simulations. Although it is beyond the scope of this study, the short period of convection in the E5SIT-Tied simulation likely allows more shortwave radiation to warm ocean regions, enhancing the SST, and further destabilizes atmosphere, causing positive feedback between convection and SST. This feedback strengthens the convective responses to SST and hinders the 
coupling of convection with large-scale circulation patterns such as those in the MJO. Therefore, the holistic consideration of moist convection and air-sea coupling is necessary to improve the representation of the MJO in climate models. This premise warrants further investigation.

\section{Conclusion}

We conducted experiments using the ECHAM model with one-column high resolution ocean model to investigate the key processes for MJO propagation over the MC in climate simulations. With models with better representation of air-sea coupling, we demonstrated that convection-circulation coupling is crucial to the modeling of MJO propagation over the MC. E5SIT-Tied simulates less moisture buildup over the $\mathrm{MC}$ when the deep convection in phases 1 and 2 is necessary for the propagation of the MJO over the MC. The E5SIT-Tied simulation, which does not model MJO propagation, produces local MSE anomaly which is greatly correlated with local deep convection over the MC, in contrast to the shallow convection simulated by E5SITNord. Such rapid development of deep convection over the $\mathrm{MC}$ creates an environment that is less conducive to MJO propagation. Differences in low-level moistening in relation to light rain events between the two simulations indicated that E5SIT-Tied tends to remove more moisture through convective processes in the presence of subsidence than does E5SIT-Nord. The hindcast case study of an observed MJO indicated that the environments that are less favorable for the eastward propagation of the MJO in the E5SIT-Tied simulation may be formed through weaker deep convective heating at the convective center of the MJO, which in turn leads to weaker subsidence and moisture buildup over the $\mathrm{MC}$ and the western Pacific. The present findings suggest that even with air-sea coupling, MJO propagation over the $\mathrm{MC}$ is highly dependent on the capacity of CPS to produce MJO-related convection-circulation coupling, including (1) inducing strong deep convective heating associated with convective center over the Indian Ocean and (2) forming a favorable environment characterized by low-level moistening under the effects of a subsidence branch to the east of convective center. If CPSs are capable of this, convection-circulation coupling is reinforced, and the maintenance of convective processes of the MJO over the MC is facilitated. Our analysis indicates that the instantaneous response of CPS to MJO-related environmental changes can further affect intraseasonal variability in climate models; thus, the response of CPS must be carefully designed. Our analysis may be used as a process-based diagnostic for evaluating convection-circulation coupling in the MJO. Our findings can help model developers resolve the challenge of the
"MJO barrier" over the MC, helping them better forecast MJO in their climate models.

Supplementary Information The online version contains supplementary material available at https://doi.org/10.1007/s00382-021-06013-2.

Acknowledgements We thank three anonymous reviewers providing constructive comments and suggestions to help this study be more complete. This work was supported by the Taiwan Ministry of Science and Technology under grant numbers MOST 110-2111-M-001-010, MOST107-2111-M-001-010, MOST 109-2111-M-001-012-MY3, MOST 110-2811-M-001-633 and MOST 110-2123-M-001-003. We are also grateful to the National Center for High-Performance Computing for providing the facilities for the computational procedures and to the Max Planck Institute for Meteorology, which developed the ECHAM5. All the model data presented here can be obtained by contacting the corresponding author Dr. Wan-Ling Tseng (wtseng@ gate.sinica.edu.tw).

Open Access This article is licensed under a Creative Commons Attribution 4.0 International License, which permits use, sharing, adaptation, distribution and reproduction in any medium or format, as long as you give appropriate credit to the original author(s) and the source, provide a link to the Creative Commons licence, and indicate if changes were made. The images or other third party material in this article are included in the article's Creative Commons licence, unless indicated otherwise in a credit line to the material. If material is not included in the article's Creative Commons licence and your intended use is not permitted by statutory regulation or exceeds the permitted use, you will need to obtain permission directly from the copyright holder. To view a copy of this licence, visit http://creativecommons.org/licenses/by/4.0/.

\section{References}

Adames ÁF (2017) Precipitation Budget of the Madden-Julian Oscillation. J Atmos Sci 74(6):1799-1817. https://doi.org/10.1175/ JAS-D-16-0242.1

Adler RF, Huffman GJ, Chang A et al (2003) The version-2 global precipitation climatology project (GPCP) monthly precipitation analysis (1979-present). J Hydrometeorol 4:1147-1167. https:// doi.org/10.1175/1525-7541(2003)004\%3c1147:TVGPCP\%3e2.0. $\mathrm{CO} ; 2$

Ahn M-S, Kim D, Ham Y-G, Park S (2020a) Role of maritime continent land convection on the mean state and MJO propagation. J Clim 33:1659-1675. https://doi.org/10.1175/JCLI-D-19-0342.1

Ahn M, Kim D, Kang D et al (2020b) MJO propagation across the maritime continent: are CMIP6 models better than cmip5 models? Geophys Res Lett. https://doi.org/10.1029/2020GL087250

Andersen JA, Kuang Z (2012) Moist static energy budget of MJO-like disturbances in the atmosphere of a zonally symmetric aquaplanet. J Clim 25:2782-2804

Banzon VF, Reynolds RW, Stokes D, Xue Y (2014) A 1/4º-spatialresolution daily sea surface temperature climatology based on a blended satellite and in situ analysis. J Clim 27:8221-8228. https://doi.org/10.1175/JCLI-D-14-00293.1

Benedict JJ, Randall DA (2007) Observed characteristics of the MJO relative to maximum rainfall. J Atmos Sci 64:2332-2354

Benedict JJ, Randall DA (2011) Impacts of idealized air-sea coupling on Madden-Julian oscillation structure in the superparameterized CAM. J Atmos Sci 68:1990-2008. https://doi.org/10.1175/ JAS-D-11-04.1 
Bernie DJ, Woolnough SJ, Slingo JM, Guilyardi E (2005) Modeling diurnal and intraseasonal variability of the ocean mixed layer. $\mathbf{J}$ Clim 18:1190-1202

Ciesielski PE, Johnson RH, Jiang X et al (2017) Relationships between radiation, clouds, and convection during DYNAMO. J Geophys Res Atmos 122:2529-2548

CLIVAR Madden-Julian Oscillation working group (2009) MJO simulation diagnostics. J Clim 22:3006-3030. https://doi.org/10.1175/ 2008JCLI2731.1

Cravatte S, Picaut J, Eldin G (2003) Second and first baroclinic Kelvin modes in the equatorial Pacific at intraseasonal timescales. J Geophys Res 108:22-1-22-20. https://doi.org/10.1029/2002JC001511

Crueger T, Stevens B, Brokopf R (2013) The Madden-Julian oscillation in ECHAM6 and the introduction of an objective MJO metric. J Clim 26:3241-3257. https://doi.org/10.1175/JCLI-D-12-00413.1

Dee DP, Uppala SM, Simmons AJ et al (2011) The ERA-Interim reanalysis: configuration and performance of the data assimilation system. Q J R Meteorol Soc 137:553-597. https://doi.org/ 10.1002/qj.828

Del Genio AD, Chen Y (2015) Cloud-radiative driving of the Madden-Julian oscillation as seen by the A-Train. J Geophys Res Atmos 120:5344-5356

DeMott CA, Klingaman NP, Woolnough SJ (2015) Atmosphereocean coupled processes in the Madden-Julian oscillation. Rev Geophys 53:1099-1154

DeMott CA, Wolding BO, Maloney ED, Randall DA (2018) Atmospheric mechanisms for MJO decay over the maritime continent. J Geophys Res Atmos 123:5188-5204. https://doi.org/10.1029/ 2017JD026979

DeMott CA, Klingaman NP, Tseng W et al (2019) The convection connection: how ocean feedbacks affect tropical mean moisture and MJO propagation. J Geophys Res Atmos 124:11910-11931. https://doi.org/10.1029/2019JD031015

Deng L, Wu X (2010) Effects of convective processes on GCM simulations of the Madden-Julian oscillation. J Clim 23:352-377

Duchon CE (1979) Lanczos filtering in one and two dimensions. J Appl Meteorol 18:1016-1022. https://doi.org/10.1175/15200450(1979)018\%3c1016:LFIOAT\%3e2.0.CO;2

Fiedler S, Crueger T, D’Agostino R et al (2020) Simulated tropical precipitation assessed across three major phases of the coupled model intercomparison project (CMIP). Mon Weather Rev 148:3653-3680. https://doi.org/10.1175/MWR-D-19-0404.1

Flatau M, Flatau PJ, Phoebus P, Niiler PP (1997) The feedback between equatorial convection and local radiative and evaporative processes: the implications for intraseasonal oscillations. J Atmos Sci 54:2373-2386

Fu X, Wang B (2009) Critical roles of the stratiform rainfall in sustaining the Madden-Julian oscillation: GCM experiments*. J Clim 22:3939-3959. https://doi.org/10.1175/2009JCLI2610.1

Gaspar P, Grégoris Y, Lefevre J-M (1990) A simple eddy kinetic energy model for simulations of the oceanic vertical mixing: tests at station Papa and long-term upper ocean study site. J Geophys Res 95:16179. https://doi.org/10.1029/JC095iC09p 16179

Hagos SM, Zhang C, Feng Z et al (2016) The impact of the diurnal cycle on the propagation of Madden-Julian oscillation convection across the maritime continent. J Adv Model Earth Syst 8:15521564. https://doi.org/10.1002/2016MS000725

Hannah WM, Maloney ED (2014) The moist static energy budget in NCAR CAM5 hindcasts during DYNAMO. J Adv Model Earth Syst 6:420-440. https://doi.org/10.1002/2013MS000272

Heath A, Gonzalez AO, Gehne M, Jaramillo A (2021) Interactions of large-scale dynamics and Madden-Julian oscillation propagation in multi-model simulations. J Geophys Res Atmos. https://doi.org/ 10.1029/2020JD033988
Hendon HH, Salby ML (1996) Planetary-scale circulations forced by intraseasonal variations of observed convection. J Atmos Sci 53:1751-1758. https://doi.org/10.1175/1520-0469(1996)053\% 3c1751:PSCFBI\%3e2.0.CO;2

Hsu H-H, Weng C-H, Wu C-H (2004) Contrasting characteristics between the Northward and Eastward propagation of the intraseasonal oscillation during the boreal summer. J Clim 17:727743. https://doi.org/10.1175/1520-0442(2004)017\%3c0727: CCBTNA\%3e2.0.CO;2

Janiga MA, Schreck CJ III, Ridout JA et al (2018) Subseasonal forecasts of convectively coupled equatorial waves and the MJO: Activity and predictive skill. Mon Weather Rev 146:2337-2360

Jiang X (2017) Key processes for the eastward propagation of the Madden-Julian oscillation based on multimodel simulations. J Geophys Res Atmos 122:755-770. https://doi.org/10.1002/2016J D025955

Jiang X, Waliser DE, Olson WS et al (2011) Vertical diabatic heating structure of the MJO: intercomparison between recent reanalyses and TRMM estimates. Mon Weather Rev 139:3208-3223

Jiang X, Waliser DE, Xavier PK et al (2015) Vertical structure and physical processes of the Madden-Julian oscillation: exploring key model physics in climate simulations. J Geophys Res Atmos 120:4718-4748. https://doi.org/10.1002/2014JD022375

Jiang X, Zhao M, Maloney ED, Waliser DE (2016) Convective moisture adjustment time scale as a key factor in regulating model amplitude of the Madden-Julian Oscillation. Geophys Res Lett 43:10-412

Jiang X, Adames ÁF, Zhao M et al (2018) A unified moisture mode framework for seasonality of the Madden-Julian oscillation. J Clim 31:4215-4224

Jiang X, Su H, Waliser DE (2019) A Damping effect of the maritime continent for the Madden-Julian oscillation. J Geophys Res Atmos 124:13693-13713. https://doi.org/10.1029/2019JD031503

Jiang X, Adames ÁF, Kim D et al (2020) Fifty years of research on the Madden-Julian oscillation: recent progress, challenges, and perspectives. J Geophys Res Atmos 125:e2019JD030911

Kang I-S, Liu F, Ahn M-S et al (2013) The role of SST structure in convectively coupled Kelvin-Rossby waves and its implications for MJO formation. J Clim 26:5915-5930

Kemball-Cook S, Wang B (2001) Equatorial waves and air-sea interaction in the boreal summer intraseasonal oscillation. J Clim 14:2923-2942. https://doi.org/10.1175/1520-0442(2001)014\% 3c2923:EWAASI\%3e2.0.CO;2

Kikuchi K, Takayabu YN (2004) The development of organized convection associated with the MJO during TOGA COARE IOP: Trimodal characteristics. Geophys Res Lett. https://doi.org/10. 1029/2004GL019601

Kiladis GN, Straub KH, Haertel PT (2005) Zonal and vertical structure of the Madden-Julian oscillation. J Atmos Sci 62:2790-2809

Kim H-M (2017) The impact of the mean moisture bias on the key physics of MJO propagation in the ECMWF reforecast. J Geophys Res Atmos 122:7772-7784

Kim D, Sperber K, Stern W et al (2009) Application of MJO simulation diagnostics to climate models. J Clim 22:6413-6436. https://doi. org/10.1175/2009JCLI3063.1

Kim D, Sobel AH, Maloney ED et al (2011) A systematic relationship between intraseasonal variability and mean state bias in AGCM simulations. J Clim 24:5506-5520

Kiranmayi L, Maloney ED (2011) Intraseasonal moist static energy budget in reanalysis data. J Geophys Res Atmos 116:0148-0227. https://doi.org/10.1029/2011JD016031

Klingaman NP, Demott CA (2020) Mean state biases and interannual variability affect perceived sensitivities of the MaddenJulian oscillation to air-sea coupling. J Adv Model Earth Syst 12:e2019MS001799 
Klingaman NP, Woolnough SJ, Weller H, Slingo JM (2011) The impact of finer-resolution air-sea coupling on the intraseasonal oscillation of the Indian monsoon. J Clim 24:2451-2468

Klingaman NP, Martin GM, Moise A (2017) ASoP (v1.0): a set of methods for analyzing scales of precipitation in general circulation models. Geosci Model Dev 10:57-83. https://doi.org/10. 5194/gmd-10-57-2017

Lappen C-L, Schumacher C (2014) The role of tilted heating in the evolution of the MJO. J Geophys Res Atmos 119:2966-2989. https:// doi.org/10.1002/2013JD020638

Liu P, Wang B, Sperber KR et al (2005) MJO in the NCAR CAM2 with the Tiedtke Convective Scheme*. J Clim 18:3007-3020. https:// doi.org/10.1175/JCLI3458.1

Ma H-Y, Zhou C, Zhang Y et al (2021) A multi-year short-range hindcast experiment with CESM1 for evaluating climate model moist processes from diurnal to interannual timescales. Geosci Model Dev 14:73-90. https://doi.org/10.5194/gmd-14-73-2021

Madden RA, Julian PR (1972) Description of global-scale circulation cells in the tropics with a 40-50 day period. J Atmos Sci 29:1109-1123. https://doi.org/10.1175/1520-0469(1972)029\% 3c1109:DOGSCC\%3e2.0.CO;2

Maloney ED (2009) The moist static energy budget of a composite tropical intraseasonal oscillation in a climate model. J Clim 22:711-729. https://doi.org/10.1175/2008JCLI2542.1

Maloney ED, Hartmann DL (1998) Frictional moisture convergence in a composite life cycle of the Madden-Julian oscillation. J Clim 11:2387-2403

Maloney ED, Sobel AH (2004) Surface fluxes and ocean coupling in the tropical intraseasonal oscillation. J Clim 17:4368-4386. https://doi.org/10.1175/JCLI-3212.1

Maloney ED, Adames ÁF, Bui HX (2019) Madden-Julian oscillation changes under anthropogenic warming. Nat Clim Change 9(1):2633. https://doi.org/10.1038/s41558-018-0331-6

Milliff RF, Madden RA (1996) The existence and vertical structure of fast, eastward-moving disturbances in the equatorial troposphere. $\mathbf{J}$ Atmos Sci 53:586-597. https://doi.org/10.1175/1520-0469(1996) 053\%3c0586:TEAVSO\%3e2.0.CO;2

Miyakawa T, Takayabu YN, Nasuno T et al (2012) Convective momentum transport by rainbands within a Madden-Julian oscillation in a global nonhydrostatic model with explicit deep convective processes. Part I: methodology and general results. J Atmos Sci 69:1317-1338. https://doi.org/10.1175/JAS-D-11-024.1

Möbis B, Stevens B (2012) Factors controlling the position of the Intertropical Convergence Zone on an aquaplanet. J Adv Model Earth Syst 4:1942-2466. https://doi.org/10.1029/2012MS000199

Nitta T, Esbensen S (1974) Heat and moisture budget analyses using BOMEX data. Mon Weather Rev 102:17-28. https://doi.org/10. 1175/1520-0493(1974)102\%3c0017:HAMBAU\%3e2.0.CO;2

Nordeng T (1994) Extended versions of the convection parametrization scheme at ECMWF and their impact upon the mean climate and transient activity of the model in the tropics. Res Dep Tech Memo 206:41

Peters K, Crueger T, Jakob C, Möbis B (2017) Improved MJO-simulation in ECHAM6.3 by coupling a stochastic multicloud model to the convection scheme. J Adv Model Earth Syst 9:193-219. https://doi.org/10.1002/2016MS000809

Roeckner E, Brokopf R, Esch M et al (2006) Sensitivity of simulated climate to horizontal and vertical resolution in the ECHAM5 atmosphere model. J Clim 19:3771-3791. https://doi.org/10.1175/ JCLI3824.1

Roeckner E, Bäuml G, Bonaventura L et al (2003) The atmospheric general circulation model ECHAM5. Part I: Model description. Hamburg, Germany

Salby ML, Hendon HH (1994) Intraseasonal behavior of clouds, temperature, and motion in the Tropics. J Atmos Sci 51:2207-2207
Tiedtke M (1989) A comprehensive mass flux scheme for cumulus parameterization in large-scale models. Mon Weather Rev 117:1779-1800. https://doi.org/10.1175/1520-0493(1989)117\% 3c1779:ACMFSF\%3e2.0.CO;2

Tseng W-L, Tsuang B-J, Keenlyside NS et al (2015) Resolving the upper-ocean warm layer improves the simulation of the MaddenJulian oscillation. Clim Dyn 44:1487-1503. https://doi.org/10. 1007/s00382-014-2315-1

Tseng W-L, Hsu H-H, Keenlyside N et al (2017) Effects of surface orography and land-sea contrast on the Madden-Julian oscillation in the maritime continent: a numerical study using ECHAM5-SIT. J Clim 30:9725-9741. https://doi.org/10.1175/JCLI-D-17-0051.1

Tsuang B-J, Tu C-Y, Tsai J-L et al (2009) A more accurate scheme for calculating Earth's skin temperature. Clim Dyn 32:251-272. https://doi.org/10.1007/s00382-008-0479-2

Tu C-Y, Tsuang B-J (2005) Cool-skin simulation by a one-column ocean model. Geophys Res Lett. https://doi.org/10.1029/2005G L024252

Waliser DE, Lau KM, Kim J-H (1999) The influence of coupled sea surface temperatures on the Madden-Julian oscillation: a model perturbation experiment. J Atmos Sci 56:333-358

Wang B, Rui H (1990) Dynamics of the coupled moist Kelvin-Rossby wave on an equatorial $\beta$-plane. J Atmos Sci 47:397-413. https:// doi.org/10.1175/1520-0469(1990)047\%3c0397:DOTCMK\% 3e2.0.CO;2

Wang L, Li T, Maloney E, Wang B (2017) Fundamental causes of propagating and nonpropagating MJOs in MJOTF/GASS models. J Clim 30:3743-3769. https://doi.org/10.1175/JCLI-D-16-0765.1

Wheeler MC, Hendon HH (2004) An all-season real-time multivariate MJO index: development of an index for monitoring and prediction. Mon Weather Rev 132:1917-1932. https://doi.org/10.1175/ 1520-0493(2004)132\%3c1917:AARMMI\%3e2.0.CO;2

Wu X, Deng L, Song X et al (2007) Impact of a modified convective scheme on the Madden-Julian oscillation and El Niño-Southern oscillation in a coupled climate model. Geophys Res Lett. https:// doi.org/10.1029/2007GL030637

Yanai M, Esbensen S, Chu J-H (1973) Determination of bulk properties of tropical cloud clusters from large-scale heat and moisture budgets. J Atmos Sci 30:611-627. https://doi.org/10.1175/15200469(1973)030\%3c0611:DOBPOT\%3e2.0.CO;2

Zhang C (2005) Madden-Julian oscillation. Rev Geophys 43:RG2003. https://doi.org/10.1029/2004RG000158

Zhang GJ, Mu M (2005) Effects of modifications to the Zhang-McFarlane convection parameterization on the simulation of the tropical precipitation in the National Center for Atmospheric Research Community Climate Model, version 3. J Geophys Res D Atmos 110:1-12. https://doi.org/10.1029/2004JD005617

Zhang GJ, Song X (2009) Interaction of deep and shallow convection is key to Madden-Julian oscillation simulation. Geophys Res Lett 36:L09708. https://doi.org/10.1029/2009GL037340

Zhou L, Neale BR, Jochum M, Murtugudde R (2012) Improved Madden-Julian oscillations with improved physics: the impact of modified convection parameterizations. J Clim 25:1116-1136

Zhu Y, Li T (2020) Two-way interactions between MJO and highfrequency waves over the Maritime Continent in MJOTF/GASS models. Clim Dyn 54:1217-1231. https://doi.org/10.1007/ s00382-019-05054-y

Publisher's Note Springer Nature remains neutral with regard to jurisdictional claims in published maps and institutional affiliations. 